\title{
Testing Reanalyses in Constraining Dynamical Downscaling
}

\author{
Delei LI \\ Helmholtz-Zentrum Geesthacht Centre for Materials and Coastal Research, Geesthacht, Germany
}

Hans von STORCH

Helmholtz-Zentrum Geesthacht Centre for Materials and Coastal Research, Geesthacht, Germany; Center of Excellence CliSAP, University of Hamburg, Hamburg, Germany

and

\section{Beate GEYER}

Helmholtz-Zentrum Geesthacht Centre for Materials and Coastal Research, Geesthacht, Germany

(Manuscript received 29 November 2014, in final form 17 July 2015)

\begin{abstract}
Reanalysis data sets have been widely used in regional climate dynamical downscaling studies. In this study, we test the use of various reanalysis data sets in constraining dynamical downscaling by assessing the reconstruction skill of the Yellow Sea coastal winds using the COSMO model in Climate Mode (CCLM) with 7-km resolution. Four reanalysis forcing data sets are used as lateral boundary conditions and internal large-scale constraints (spectral nudging): the National Centers for Environmental Prediction and National Center for Atmospheric Research (NCEP/NCAR) reanalysis data set (NCEP1) is downscaled to an intermediate domain with 55-km resolution (CCLM_55km), ERA-interim reanalysis data set (ERAint), NCEP climate forecast system reanalysis data set (CFSR), and Japanese 55-year reanalysis data set (JRA55).

Several statistical analysis methods are employed to assess the modeled winds through comparison with observed offshore wind data from 2006, and it is found that the downscaled simulations yield good quality wind speed products. However, they all tend to overestimate observed low wind speeds and underestimate observed high wind speeds. Furthermore, the quality of the modeled wind direction is strongly associated with the wind speed intensities, exhibiting a much better reproduction of wind direction at strong wind speeds than at light wind speeds.

The downscaling simulations driven by ERAint, JRA55, and CFSR are consistent with each other in the reproduction of local wind speed and direction; the simulations driven by ERAint and JRA55 are slightly better for strong winds and those driven by CFSR are better for light winds. All three simulations generate local wind estimates that are superior to those of the simulation driven by CCLM_55km. This superiority reflects the better quality of the CFSR, ERAint, and JRA55 reanalyses with regard to assimilated local observations compared with the CCLM_55km hindcast, which exploits only upper-air large scale NCEP1 wind fields.
\end{abstract}

Keywords ocean surface wind; COSMO-CLM; dynamical downscaling; reanalysis

Corresponding author: Delei Li, Helmholtz-Zentrum

Geesthacht Centre for Materials and Coastal Research,

Max-Planck-Str. 1, 21502 Geesthacht, Germany

E-mail: delei.li@hzg.de

(C)2016, Meteorological Society of Japan 


\section{Introduction}

Ocean surface wind is a fundamental parameter of considerable importance to climatological, oceanographical, and meteorological research. It is related to various processes in the earth system, including wind-induced ocean general circulation, wind-wave generation, ocean phytoplankton blooms, and oceanographic down- or upwelling events (e.g., Enriquez and Friehe 1995; Liu et al. 2014; Toba et al. 1990; Wunsch 1998; Young et al. 2011). Ocean surface wind is also critically important to the momentum, mass, and energy fluxes between the ocean and the atmosphere, which is crucial information for understanding air-sea interactions; the variability of the global energy and water cycle; and long-term climate fluctuations and trends (Atlas et al. 2011).

The coastal area, which is home to two-thirds of the world's population (Artioli et al. 2005), has been seriously affected by these wind-related oceanic and atmospheric phenomena. A better understanding of coastal wind variability is essential not only from an academic point of view but also for many marine and coastal applications such as wind farms, coastal defense, and risk assessments.

To assess the trends, extremes, and variability of coastal winds, many efforts have been made to gather and generate long-term homogeneous wind data sets. Unfortunately, in situ observations, which typically include oceanographic buoy and ship or vessel measurements, suffer from serious limitations in terms of both spatial and temporal coverages, causing such observations to be unrepresentative of the wind regime over wide areas of ocean. They also suffer temporal inhomogeneity problems because of changes in the instrumentation, observational practices, and surroundings of observation stations. However, satellite observations, which have the advantage of extended spatial coverage compared with buoy or ship measurements, are not available near the coast.

Additional available long-term homogeneous wind data sets originate from global or regional reanalysis. The most famous and commonly used global atmospheric reanalysis data sets are the National Centers for Environmental Prediction and National Center for Atmospheric Research (NCEP/NCAR) reanalysis data set (NCEP1, Kalnay et al. 1996), the European Center for Medium-Range Weather Forecasts (ECMWF) 45-year reanalysis data set (ERA-40, Uppala et al. 2005), and the Japanese 25-year Reanalysis data set (JRA25, Onogi et al. 2007). Although these reanalyses are assumed to reliably describe global large- scale dynamics, they cannot effectively resolve meso-scale dynamics or coastal wind conditions as the spatial resolution of most global reanalyses is in the range of $300-800 \mathrm{~km}$ or more (as opposed to the higher grid resolution, cf. Pielke 1991). Regional reanalysis offers advantages over global reanalysis in resolving finer-scale dynamics; however, it is generally complex and time consuming due to the complicated data assimilation process that is required (e.g., the North American Regional Reanalysis, NARR). As a much simpler and less expensive alternative, global reanalyses can be dynamically downscaled using regional climate models (RCMs) to obtain long-term homogenous variables. Techniques, such as spectral nudging (von Storch et al. 2000) or scale-selective bias correction (Kanamaru and Kanamitsu 2007), have also been applied to improve reproduction quality (Weisse and von Storch 2010).

Such regional reconstructions, which offer higher spatial resolutions and a more detailed representations of surface boundary conditions (i.e., orography, coastline, and vegetation), are expected to better describe processes on scales below that of the reanalysis resolution such as low-level meso-scale frontogenesis or meso-scale disturbances (e.g., Denis et al. 2002). Therefore, realistic local wind conditions and climatologies at high resolutions are expected to be captured by these meso-scale meteorological models.

Recently, several studies have been conducted to investigate the accuracy of meso-scale simulations of ocean surface wind by comparing them with buoy or satellite wind data from specific local areas (e.g., Accadia et al. 2007; Berge et al. 2009; Carvalho et al. 2012; Jimenez et al. 2007; Penabad et al. 2008; Shimada et al. 2011; Sousa et al. 2013; Winterfeldt et al. 2011; Winterfeldt and Weisse 2009). Accadia et al. (2007) compared simulated wind and Quick Scatterometer (QuikSCAT) observed wind over the entire Mediterranean Sea. They identified a lower simulated wind quality in certain critical areas surrounded by complex orography in the Mediterranean Sea and demonstrated that numerical damping was a likely factor in reducing the simulated wind strength. Carvalho et al. (2012) assessed the simulated winds based on various reanalyses against data observed along the coast of the Iberian Peninsula and determined that in the study area, the more recently generated reanalyses (i.e., ERA-Interim and NCEP-CFSR) perform better for ocean wind simulations than do the older reanalyses. Sousa et al. (2013) assessed the accuracy of QuikSCAT-observed and modeled wind patterns along the Galician coast 
through verification against buoy-observed wind data and revealed that the model demonstrated some advantages in the representation of near-shore wind conditions compared with the QuikSCAT satellite data, and Carvalho et al. (2014a) concluded that WRF simulated wind is the best alternative to in situ observed offshore wind compared with satellite, analyses, and reanalyses data along the Iberian Peninsula coast. Winterfeldt et al. (2011) used QuikSCAT Level 2B $12.5-\mathrm{km}$ data to detect added value for near-surface wind speeds from a large scale constrained RCM over northern Europe and demonstrated that the regional modeled wind provided added value with respect to the reanalysis wind speed in coastal areas with complex orography.

Their results have shown that the meso-scale meteorological models are capable of deriving the local wind conditions realistically at high resolution. However, most of these studies have investigated the ocean surface winds in European or North American offshore regions. In the present study, particular attention is focused on the coastal area of the Yellow Sea. The climate of the Yellow Sea is dominated by the East Asian Monsoon, with prevailing northerly or northwesterly winds in winter and predominantly southerly or southeasterly winds in summer; intense winds typically occur during the winter season $(\mathrm{Su}$ and Yuan 2005). The wind conditions in the coastal area, however, are variable due to the complex coastal orography and orientation.

Wang et al. (2004) have demonstrated that the skill of RCMs is highly dependent on the quality of the driving data. To capture the coastal winds in the Yellow Sea, several different reanalysis data sets are used to constrain high-resolution simulations over this area, and the downscaled coastal winds are compared against several offshore observations (Fig. 1). The paper is organized as follows. Section 2 describes the forcing data sets, hindcast simulations, observations, and assessment methods used in this study. The results are presented in Section 3, including the characteristics of the observed winds and performance of the hindcasts driven by different forcing data sets. The discussion and conclusions are given in Sections 4 and 5, respectively.

\section{Data sets and methods}

\subsection{Forcing data sets}

The initial and boundary conditions for a regional meteorological model, which are generally obtained from reanalysis data sets, are of fundamental importance. To quantify the potential for inter-reanalysis

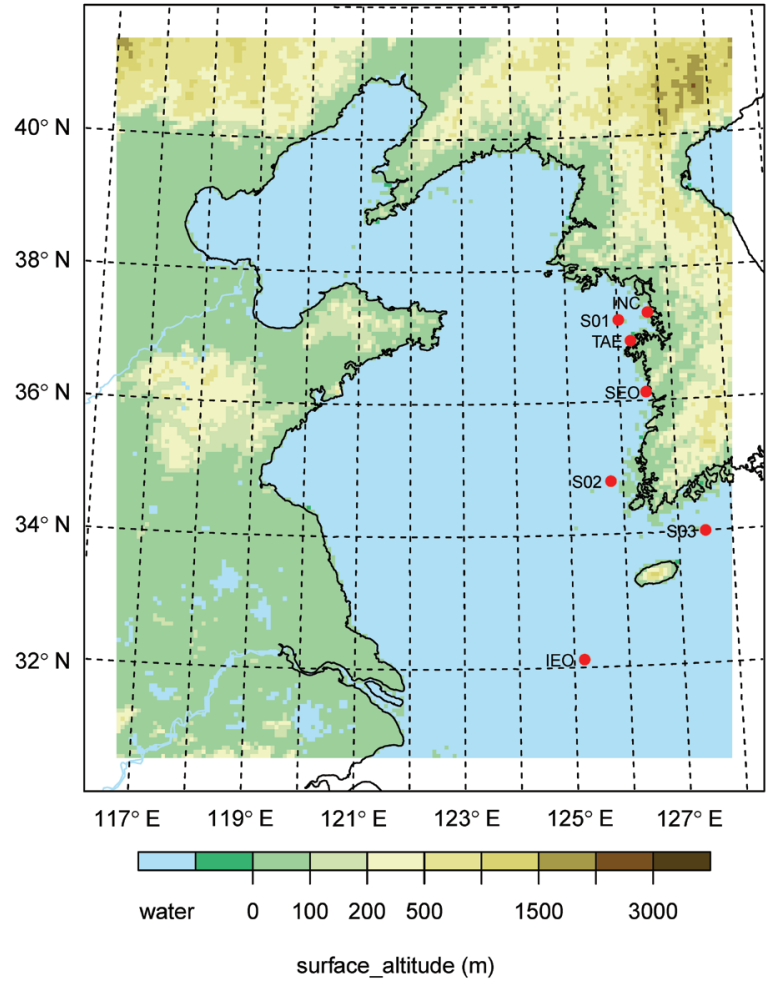

Fig. 1. Orography of the simulation domain and locations of the wind observations.

differences, four major reanalysis data sets were used: NCEP1 (Kalnay et al. 1996), CFSR (Saha et al. 2010), ERAint (Dee et al. 2011), and JRA55 (Ebita et al. 2011).

The global reanalysis of atmospheric fields, NCEP1, is a joint project of NCEP/NCAR with the intent of supporting the needs of the research and climate monitoring communities (Kistler et al. 2001). For this reanalysis, a state-of-the-art analysis system is applied to perform data assimilation using quality-controlled data from 1948 to the present. NCEP1 provides a complete history of the global states of the atmosphere with a horizontal grid resolution of approximately $210 \mathrm{~km}$ (T62 spectral truncation) and 28 pressure levels in the vertical direction. The product is mostly homogeneous, but a number of significant inhomogeneities have been detected, e.g., by Vecchi et al. (2013) and Klehmet (2014). The fact that it is continuously updated to include the recent past makes it one of the longest, most up-to-date, and most valuable data sets for the studies of long-term climate variability and change (Weisse and von Storch 2010). 
The CFSR is a global high-resolution data set derived using a coupled atmosphere-ocean-sea ice-land system, and it provides an optimized estimate of the state of this coupled system over the period 1979-2010. Compared with the NCEP1 reanalysis, it has several additional features, including 1) the coupling of the atmosphere and ocean with an interactive sea ice component during the generation of 6-h guess fields, 2) a higher horizontal grid resolution (approximately $38 \mathrm{~km}, \mathrm{~T} 382$ ) for the atmospheric fields, and 3) the assimilation of satellite radiances using the gridpoint statistical interpolation scheme rather than the derived temperature and humidity values (Saha et al. 2010; Wang et al. 2011). The CFSR reanalysis has been used in various types of studies, including climate diagnosis and ocean wave climatology (e.g., Chelliah et al. 2011; Chawla et al. 2013). In this study, we used the pre-processed CFSR data with a $50-\mathrm{km}$ resolution provided by the CLM community (http://www.clm-community.eu/) as a forcing data set.

The ERAint reanalysis represents a third-generation global atmospheric reanalysis produced by the ECMWF. A much-improved atmospheric model and assimilation system were used for this reanalysis compared with those used in ERA-40, and it has a much higher spatial resolution (T255, approximately $80 \mathrm{~km}$ in the horizontal direction and 60 levels in the vertical direction). Its representations of low-frequency variability and stratospheric circulation are also improved compared with that of ERA-40 (Dee et al. 2011; Dee and NCAR staff 2013).

The JRA55 reanalysis is also a third-generation reanalysis, which covers the period 1958-2012 and was conducted by the Japan Meteorological Agency. The model grid data were released in March 2014. Compared with its predecessor, JRA25, many improvements were implemented for JRA55, including a higher spatial resolution (T319L60, approximately $60 \mathrm{~km}$ in the horizontal direction and 60 levels in the vertical direction) as well as the adoption of a new radiation scheme and four-dimensional variational data assimilation with variational bias correction for satellite radiances (Ebita et al. 2011).

\subsection{Regional atmospheric hindcasts}

The RCM used in this study is COSMO-CLM version 4.14 (the Consortium for Small-scale Modelling in Climate Mode, here abbreviated CCLM). It is a three-dimensional non-hydrostatic model, which was originally used for operational weather predictions and has further evolved for use in running climatology simulations (Böhm et al. 2006; http://www.clm-community.eu/). The CCLM calculates atmospheric variables based on thermo-hydrodynamical primitive equations that describe a compressible flow in a moist atmosphere in rotated geographical coordinates and a generalized terrain-following height coordinate (Doms and Schättler 2002). The numerical integration for these simulations is performed using the Runge-Kutta scheme with a time step of $60 \mathrm{~s}$ (Baldauf et al. 2011). The convection is parameterized as described by Tiedtke (1989). For the microphysics, a Kessler-type scheme (Kessler 1969), which includes snow and cloud ice processes, has been chosen. The radiation scheme is adopted from Ritter and Geleyn (1992), and the multilayer soil model TERRA-ML (Schrodin and Heise 2002), with nine soil layers, is also part of the CCLM.

In this study, four climate simulations for the year 2006 are investigated using the CCLM. These simulations are forced by the various reanalysis data sets mentioned in the previous section, which are employed as initial and lateral boundary conditions. Furthermore, the large scale components of the horizontal wind field are used to constrain the simulations by means of an interior spectral nudging method (von Storch et al. 2000) at every third time step at levels above $850 \mathrm{hPa}$. The purpose of the spectral nudging technique is to keep the model solution close to the reanalysis values at large scales while, at the same time, allowing the model to be free to resolve small scales and regional phenomena without the influence of the forcing data. Spectral nudging is used instead of typical grid nudging because of the risk of over forcing the RCMs at small scales via grid nudging. Liu et al. (2012) have concluded that spectral nudging with the appropriate choice of wave numbers provides an advantage over grid nudging when balancing a simulation for the reproduction of both large and small scales. The calculation of significant wave numbers for spectral nudging is based on the utility developed by Burkhardt Rockel (http:// www.clm-community.eu/index.php?menuid=230\&reporeid=331).

The first simulation is double-nested downscaling of the NCEP1 reanalysis. The first downscaling covers East Asia and the Western Pacific Ocean with a $0.5^{\circ}$ grid resolution (approximately $55 \mathrm{~km}$ ) and 32 vertical levels using the CCLM (hereafter called CCLM_55km, Barcikowska 2012). The second downscaling, which is nested in the CCLM_55km, is performed for the Bohai and Yellow Sea region (Fig. 1 ) with a grid resolution of $0.0625^{\circ}$ (approximately. 
Table 1. List of wind speed observation sites and associated locations (Lat, Long), numbers of valid pairs (Num.), observations types (Type) and heights (Height), and data-providing institutions.

\begin{tabular}{cccccccc}
\hline Station name & Abbreviation & Lat $\left({ }^{\circ} \mathrm{N}\right)$ & Long $\left({ }^{\circ} \mathrm{E}\right)$ & Num. & Type & Height & Institution \\
\hline IEOdo & IEO & 32.12 & 125.18 & 4539 & platform & 42 & NMDIS \\
INCheon & INC & 37.33 & 126.59 & 6920 & buoy & 3 & NMDIS \\
S22101 & S01 & 37.23 & 126.02 & 8598 & buoy & 3 & KMA \\
S22102 & S02 & 34.80 & 125.77 & 7459 & buoy & 3 & KMA \\
S22103 & S03 & 34.00 & 127.50 & 6524 & buoy & 3 & KMA \\
SEOcheon & SEO & 36.13 & 126.50 & 6842 & buoy & 3 & NMDIS \\
TAEan & TAE & 36.91 & 126.24 & 6923 & buoy & 3 & NMDIS \\
\hline
\end{tabular}

$7 \mathrm{~km}$ ) and 40 vertical levels (hereafter called CCLMNCEP1). The horizontal grid is $168 \times 190$ in the longitudinal and latitudinal directions, respectively, with an 8-grid-point sponge zone at each boundary, which is indicated by a blank frame in Fig. 1. The other three simulations are downscaled directly from the CFSR, ERAint, and JRA55 data sets, using the same CCLM setup and a high resolution of $0.0625^{\circ}$. However, the spectral nudging parameters are different because they depend on the resolution of the forcing data sets. The output is hourly for all simulations.

\subsection{Measured wind data}

In this study, the wind speeds provided by the downscaled hindcasts are validated against observations from seven ocean stations with the temporal intervals of $0.5 \mathrm{~h}$ for the year 2006. The observation data, which include buoy and platform observation data, were collected from the National Marine Data and Information Service of China (NMDIS) and Korean Meteorological Administration (KMA). Although our research domain covers the entirety of the Bohai and Yellow Seas, high-quality ocean surface observations with high temporal resolution are available only along the coastal areas of the Yellow Sea for the year 2006. The locations of the stations where these observations were recorded are depicted in Fig. 1 , and detailed information regarding the observations, including their names, coordinates, and sources, is listed in Table 1; in this table, Num. represents the number of the simultaneous and valid pairs of simulated and real wind observations for the corresponding station, with an ideal value of 8760 . The instances of fewer valid records, especially for station IEO, are the result of the unavailability of measurements for certain times or periods. The influence of the missing measurements on the comparison results is discussed in detail later. The wind data from the simu- lations correspond to a height of $10 \mathrm{~m}$; therefore, the observed wind speeds are converted to a $10-\mathrm{m}$ height by accounting for the wave dependence of the roughness length via the Charnock relation (Stull 1988).

\subsection{Evaluation measures}

The simulated winds are compared with point observations. To do so, the simulated grid-based wind data are interpolated to the station's locations using nearest-neighbor interpolation.

Several statistical measures are used to assess the quality of the simulated wind speed and direction. The bias is defined as

$$
\operatorname{Bias}=\frac{1}{N} \sum_{i=1}^{N} x_{i}^{\prime}=\frac{1}{N} \sum_{i=1}^{N}\left(x_{m i}-x_{o i}\right),
$$

where $N$ denotes the number of valid pairs of simulated and real wind observations and $x_{i}^{\prime}$ is the deviation between a modeled wind observation $\left(x_{m i}\right)$ and its real counterpart $\left(x_{o i}\right)$. Because the wind direction is a circular and nonlinear variable, a different expression is used for differences larger than $180^{\circ}$ to calculate the direction bias referred to in Carvalho et al. (2014b), which is

$$
\begin{aligned}
& x_{i}^{\prime}=\left(x_{m i}-x_{o i}\right)\left[1-\frac{360^{\circ}}{\left|x_{m i}-x_{o i}\right|}\right], \\
& \text { if }\left|x_{m i}-x_{o i}\right|>180^{\circ} .
\end{aligned}
$$

The bias quantifies the systematic errors on the wind data; a positive (negative) bias indicates a clockwise (anti-clockwise) deviation in terms of the wind direction. The root mean square error (RMSE) is defined as follows:

$$
\mathrm{RMSE}=\sqrt{\frac{1}{N} \sum_{i=1}^{N}\left(x_{i}^{\prime}\right)^{2}}
$$

The standard deviation error (STDE), which 
Table 2. Number and percentage of observations in each range of wind speed and mean wind speed at each observation site in the year 2006 .

\begin{tabular}{cccccc}
\hline \multirow{2}{*}{ Station } & $\begin{array}{c}0-4.0 \mathrm{~m} \mathrm{~s}^{-1} \\
\text { Num }(\%)\end{array}$ & $\begin{array}{c}4.0-8.0 \mathrm{~m} \mathrm{~s}^{-1} \\
\text { Num }(\%)\end{array}$ & $\begin{array}{c}8.0-12.0 \mathrm{~m} \mathrm{~s}^{-1} \\
\text { Num }(\%)\end{array}$ & $\begin{array}{c}>12.0 \mathrm{~m} \mathrm{~s}^{-1} \\
\text { Num }(\%)\end{array}$ & Mean $\left(\mathrm{m} \mathrm{s}^{-1}\right)$ \\
\hline IEO & $1162(26)$ & $2077(46)$ & $1000(22)$ & $300(7)$ & 6.37 \\
INC & $4210(61)$ & $2090(30)$ & $500(7)$ & $120(2)$ & 3.88 \\
S01 & $4414(51)$ & $2893(34)$ & $1044(12)$ & $247(3)$ & 4.66 \\
S02 & $2799(38)$ & $2929(39)$ & $1237(17)$ & $494(7)$ & 5.57 \\
S03 & $2099(32)$ & $2182(33)$ & $1495(23)$ & $748(11)$ & 6.60 \\
SEO & $3380(49)$ & $2642(39)$ & $666(10)$ & $154(2)$ & 4.65 \\
TAE & $4907(71)$ & $1338(19)$ & $491(7)$ & $187(3)$ & 3.36 \\
\hline
\end{tabular}

represents the variability of the error around its mean, is given by $\mathrm{STDE}^{2}=\mathrm{RMSE}^{2}-\mathrm{Bias}^{2}$.

\section{Results}

\subsection{The analysis of in situ observations}

To provide an overview of the general characteristics of the observed wind data, number and percentage of observations in each wind speed range and yearly mean wind speed at each observation site are summarized in Table 2. The table shows that light winds at speeds between 0 to $4 \mathrm{~m} \mathrm{~s}^{-1}$ are dominant at the stations INC, S01, SEO, and TAE, which are located north of $36^{\circ} \mathrm{N}$ and west of the Korean Peninsula and have a yearly mean wind speed of approximately 4 $\mathrm{m} \mathrm{s}^{-1}$. They generally have low percentages $(2 \%$ and $3 \%$ ) of observations of wind speeds higher than 12 $\mathrm{m} \mathrm{s}^{-1}$, whereas the other three stations, IEO, S02, and S03, observe higher wind speeds, with percentages of wind speeds above $12 \mathrm{~m} \mathrm{~s}^{-1}$ of $7 \%$ to $11 \%$ and a yearly mean wind speed of approximately $6 \mathrm{~m} \mathrm{~s}^{-1}$. By considering the locations of the observation stations given in Table 1, we find that the wind speed generally increases from north to south. Among all stations, S03 has the largest yearly mean value and highest percentage of high wind speeds above $12 \mathrm{~m} \mathrm{~s}^{-1}$, both throughout the entire year and during each season (not shown here), primarily because of the intensification caused by the topography of the Korean Peninsula and the Island of Jeju, or Tsushima.

The corresponding wind roses are shown in Fig. 2. Six of the seven stations are displayed; station S01 is omitted due to invalid wind direction measurements. The bars represent the direction of the origin of the wind. For the stations along the western coast of the Korean Peninsula, namely, INC, S02, SEO, and TAE, northerly and northwesterly winds are prevailing; winds blowing from the south, southeast, or east are observed at a lower frequency because of the monsoon influence and local orography. Northerly and northeasterly winds are common at station IEO, which is located to the south of the Yellow Sea. At station S03, the wind behavior is slightly different, with northeast and northwest winds being most frequent because of the direction of the strait between the Jeju Island and the Korean Peninsula. These results show that the wind in coastal areas is highly influenced by the local orography, with the winds tending to be aligned with the coastal orientation (Alvarez et al. 2013; Sousa et al. 2013).

\subsection{Intercomparison of downscaled wind data}

Taylor diagrams (Taylor 2001) were used to perform the intercomparison of downscaled wind data. These diagrams provide a simple means for assessing the agreement between a set of patterns and a reference data set by summarizing the metrics of the correlation, centered root mean square difference and standard deviation in a single graph. As defined by Taylor (2001), the centered root mean square difference is calculated using the same formula as that for the STDE given in Section 2.4; therefore, in the remainder of this paper, the STDE is used in lieu of the centered root mean square difference. Figure 3 shows the Taylor diagrams for the wind speed at each of the observation stations. The standard deviation and STDE are normalized with respect to the standard deviation of the observed wind data. The simulated wind product that best agrees with the observation will lie nearest to the reference point that is indicated by a blank circle on the $\mathrm{x}$ axis.

According to Fig. 3, at each station, the wind speed downscaled from NCEP1 ranks the worst among all products. However, the normalized standard deviation of CCLM-NCEP1 is nearly 1 for most stations, which indicates that the wind variability of CCLMNCEP1 is quite similar to that of the observations. 


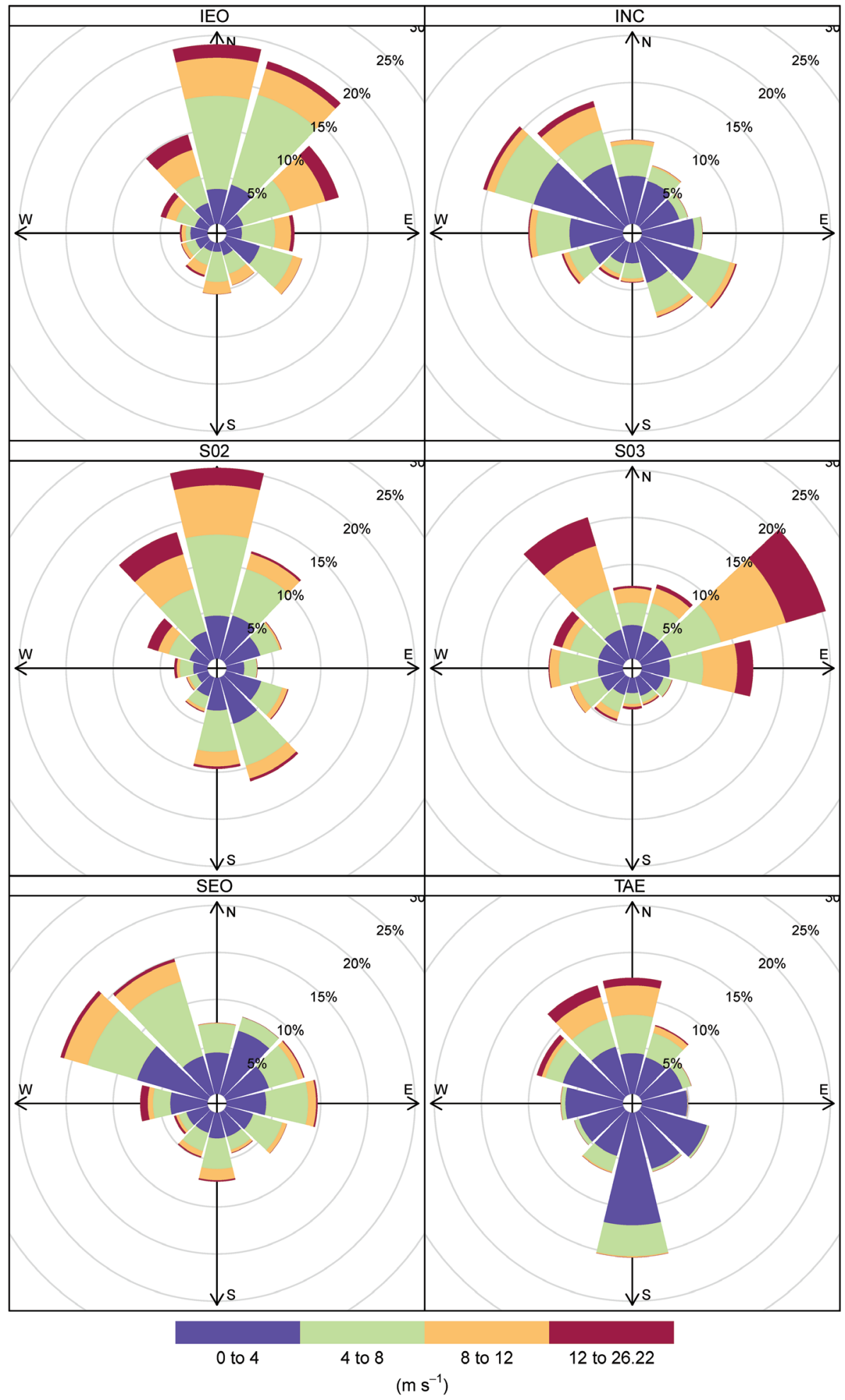

Frequency of counts by wind direction (\%)

Fig. 2. Wind rose diagrams calculated from observations recorded at six stations in 2006. The wind direction interval is $30^{\circ}$. 

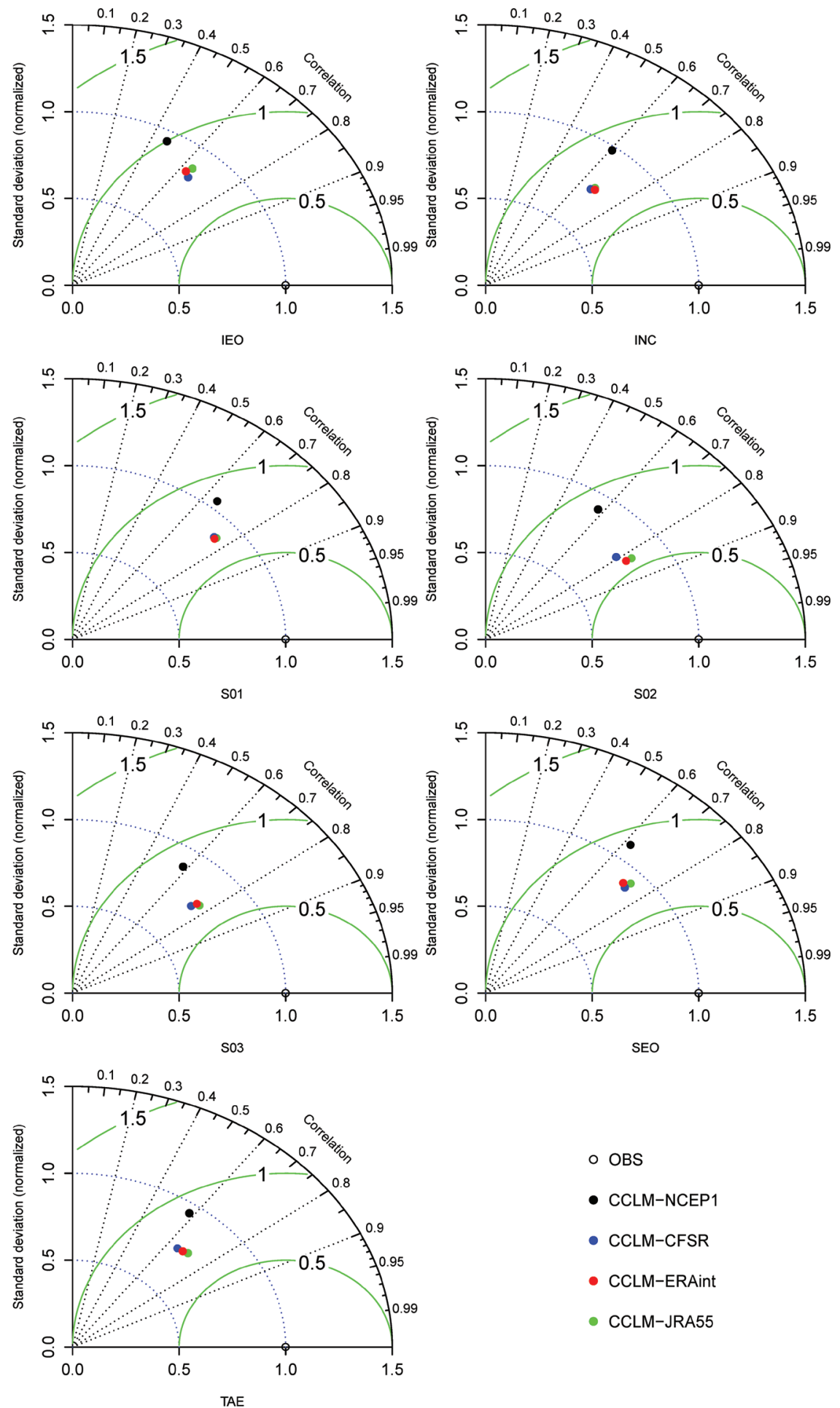

O OBS

- CCLM-NCEP1

- CCLM-CFSR

- CCLM-ERAint

- CCLM-JRA55

Fig. 3. Taylor diagrams comparing the observations with the four downscaled wind products for each station. The green contour lines represent the normalized STDE values, and the blue contour lines represent the normalized standard deviations. The correlation between the modeled and observed wind data is indicated by the azimuthal position of the point. 
Table 3. Statistical measures of the bias, STDE, and RMSE between the simulated results and the observations for each range of wind speed; unit is $\mathrm{m} \mathrm{s}^{-1}$.

\begin{tabular}{|c|c|c|c|c|c|c|c|c|c|c|c|c|c|c|c|}
\hline \multirow{2}{*}{ Simulation } & \multicolumn{3}{|c|}{$<4 \mathrm{~m} \mathrm{~s}^{-1}$} & \multicolumn{3}{|c|}{$4-8 \mathrm{~m} \mathrm{~s}^{-1}$} & \multicolumn{3}{|c|}{$8-12 \mathrm{~m} \mathrm{~s}^{-1}$} & \multicolumn{3}{|c|}{$>12 \mathrm{~m} \mathrm{~s}^{-1}$} & \multicolumn{3}{|c|}{ all } \\
\hline & Bias & STDE & RMSE & Bias & STDE & RMSE & Bias & STDE & RMSE & Bias & STDE & RMSE & Bias & STDE & RMSE \\
\hline $\begin{array}{l}\text { CCLM- } \\
\text { NCEP1 }\end{array}$ & 2.91 & 2.47 & 3.83 & 0.99 & 2.65 & 2.85 & -0.20 & 2.84 & 2.88 & -1.57 & 2.86 & 3.33 & 1.63 & 2.93 & 3.39 \\
\hline $\begin{array}{c}\text { CCLM- } \\
\text { CFSR }\end{array}$ & 1.73 & 1.80 & 2.51 & 0.06 & 1.89 & 1.95 & -1.21 & 2.02 & 2.41 & -2.81 & 2.21 & 3.61 & 0.55 & 2.29 & 2.40 \\
\hline $\begin{array}{l}\text { CCLM- } \\
\text { ERAint }\end{array}$ & 1.83 & 1.81 & 2.59 & 0.25 & 1.89 & 1.95 & -0.95 & 2.02 & 2.28 & -2.54 & 2.18 & 3.37 & 0.72 & 2.26 & 2.42 \\
\hline $\begin{array}{l}\text { CCLM- } \\
\text { JRA55 }\end{array}$ & 1.83 & 1.82 & 2.60 & 0.25 & 1.88 & 1.94 & -0.82 & 2.04 & 2.25 & -2.28 & 2.16 & 3.17 & 0.75 & 2.23 & 2.40 \\
\hline
\end{tabular}

Considering the values of the correlation and STDE between CCLM-NCEP1 and the observations, the modeled wind variability of CCLM-NCEP1 may be stochastic and may not mirror the temporal details of the observed variability. The performance of the other three downscaled wind products is almost identical. They all capture the observed wind patterns, with lower normalized STDE values of approximately 0.7 and higher correlation values that are generally larger than 0.65 and can reach as high as 0.8 , as for station $\mathrm{S} 02$. However, the wind variability is underestimated by these downscaled wind products, with the values of the normalized standard deviation of approximately 0.8 .

To assess the detailed differences and variations between each of these models and the observed wind data, the statistics were calculated for four wind speed bins and eight incoming wind direction sectors. Only simultaneous and valid pairs of modeled winds and corresponding observed winds were used, and the weighted average values are summarized in Table 3 and Table 4, respectively. The bins and sectors are classified based on the observed wind data. The best score values are indicated in bold.

From Table 3, it is evident that the bias values are positive for wind speeds below $8 \mathrm{~m} \mathrm{~s}^{-1}$ and tend to be negative for wind speeds higher than $8 \mathrm{~m} \mathrm{~s}^{-1}$ for all simulated wind products, meaning that the modeled wind products overestimate weaker winds and underestimate stronger winds. Similar conclusions have been obtained for winds simulated using the WRF model in the seas around Japan (Ohsawa et al. 2011) and in German coastal waters (Ohsawa et al. 2013). This general feature may be shared by all wind simulations based on meso-scale models or may predominantly originate from the forcing data set; further study on this issue is necessary. Furthermore, the absolute values of the bias and RMSE values are the lowest for wind speeds between 4 and $12 \mathrm{~m} \mathrm{~s}^{-1}$ compared with the values for low $\left(<4 \mathrm{~m} \mathrm{~s}^{-1}\right)$ and high $\left(>12 \mathrm{~m} \mathrm{~s}^{-1}\right)$ wind speeds, indicating that all simulations demonstrate better performance for moderate winds than for low or high winds. The values of the STDE do not exhibit a strong variation between different wind bins, instead tending to simply increase with wind speed. With the STDE being similar across the wind speed range, it is the positive/negative model bias at low/high wind speeds that manifests itself in higher RMSE values at low/high wind speeds.

Among all of the simulated wind products, the CCLM-CFSR demonstrates the best performance at low wind speeds $\left(<4 \mathrm{~m} \mathrm{~s}^{-1}\right)$, followed by CCLMERAint and CCLM-JRA55. For moderate winds between 4 and $8 \mathrm{~m} \mathrm{~s}^{-1}$, the bias of CCLM-CFSR is the lowest, and the STDE and RMSE values are quite similar for CCLM-CFSR, CCLM-ERAint, and CCLM-JRA55, with CCLM-JRA55 being slightly better. CCLM-NCEP1 demonstrates the worst performance for wind speeds below $8 \mathrm{~m} \mathrm{~s}^{-1}$. For wind speeds higher than $8 \mathrm{~m} \mathrm{~s}^{-1}$, CCLM-JRA55 is generally the best, followed by CCLM-ERAint. Although CCLM-NCEP1 exhibits lower absolute bias values, the STDE and RMSE values are not as satisfactory. Overall, CCLM-CFSR tends to offer the best performance for the reproduction of lower wind speeds, whereas CCLM-JRA55 and CCLM-ERAint tend to offer much better performance in reproducing strong winds. In general, CCLM-NCEP1 has the worst error scores and tends to have a positive wind speed bias in comparison with the other three simulations.

From Table 4, it is apparent that the bias values are generally positive for all wind direction sectors of all 
Table 4. Statistical measures of the bias and RMSE between the simulated results and the observations for each wind direction sector (the numbers of valid observations are shown in parentheses); unit is degree.

\begin{tabular}{|c|c|c|c|c|c|c|c|c|c|c|c|c|c|c|c|c|c|c|}
\hline \multirow{2}{*}{ Simulation } & \multicolumn{2}{|c|}{ N (7265) } & \multicolumn{2}{|c|}{ NE (5520) } & \multicolumn{2}{|c|}{ E (4357) } & \multicolumn{2}{|c|}{ SE (4206) } & \multicolumn{2}{|c|}{ S (4270) } & \multicolumn{2}{|c|}{ SW (2607) } & \multicolumn{2}{|c|}{ W (3814) } & \multicolumn{2}{|c|}{ NW (7168) } & \multicolumn{2}{|c|}{ All } \\
\hline & Bias & RMSE & Bias & RMSE & Bias & RMSE & Bias & RMSE & Bias & RMSE & Bias & RMSE & Bias & RMSE & Bias & RMSE & Bias & RMSE \\
\hline $\begin{array}{l}\text { CCLM- } \\
\text { NCEP1 }\end{array}$ & 11.2 & 70.5 & 25.6 & 70.2 & 19.6 & 63.0 & 16.2 & 62.5 & 6.4 & 55.1 & -9.9 & 61.1 & -7.6 & 70.4 & -1.3 & 67.8 & 8.8 & 66.0 \\
\hline $\begin{array}{l}\text { CCLM- } \\
\text { CFSR }\end{array}$ & 4.9 & 42.1 & 2.1 & 47.3 & 0.2 & 47.7 & 0.3 & 59.4 & 3.8 & 56.5 & -4.9 & 59.7 & 2.6 & 62.9 & 7.0 & 53.7 & 2.8 & 52.1 \\
\hline $\begin{array}{l}\text { CCLM- } \\
\text { ERAint }\end{array}$ & 1.3 & 38.2 & 0.3 & 47.1 & 1.2 & 50.4 & 1.9 & 65.3 & 9.8 & 61.4 & 2.9 & 61.1 & 6.9 & 56.6 & 5.2 & 48.6 & 3.4 & 51.6 \\
\hline $\begin{array}{l}\text { CCLM- } \\
\text { JRA55 }\end{array}$ & 0.6 & 40.1 & -0.6 & 48.1 & 0.7 & 51.8 & 0.7 & 63.4 & 8.2 & 60.4 & -0.5 & 62.1 & 4.0 & 57.8 & 4.3 & 49.6 & 2.0 & 52.3 \\
\hline
\end{tabular}

simulated wind products, with the exception of winds blowing from the southwest for CCLM-JRA55, CCLM-CFSR and CCLM-NCEP1, from the west and northwest for CCLM-NCEP1, and from the northeast for CCLM-JRA55; all of the latter cases have negative wind direction biases. This result suggests that most of the models tend to rotate the winds clockwise. The performance of CCLM-NCEP1 ranks the worst among all simulations. For the other three simulations, the more frequent wind direction sectors generally have lower RMSE values. Northerly winds, which are the most common, have the lowest RMSE values (approximately $40^{\circ}$ ) among all sectors. Winds blowing from the SW and $\mathrm{W}$ sectors, which are less frequently recorded, have relatively large RMSE values (approximately $60^{\circ}$ ). It seems that the RMSE values are strongly related to the availability of valid samples in each direction sector; however, the SE and E sectors have much larger RMSE differences, even though they have similar numbers of valid samples. A possible cause for the variation in the wind direction sectors is explained below.

As shown by Carvalho et al. (2014b), a wind direction measurement in low wind speed conditions suffers higher errors, and the modeled directions of winds with weaker intensities tend to have larger variability and also larger RMSE values. Figure 4 shows the percentages of wind speed intensities in the different wind direction sectors, which are defined based on the observed winds. It shows that the percentages of wind speeds between 0 and $4 \mathrm{~m} \mathrm{~s}^{-1}$ in the SE, W, and SW direction sectors are higher than those in the other direction sectors. As a result, the wind direction accuracies achieved in the SE, SW and $\mathrm{W}$ sectors are much lower, with larger RMSE values, as shown in Table 4. Notably, the E and $\mathrm{S}$ sectors have similar percentages of low wind speeds, as shown in Fig. 4; however, the RMSE values of the $\mathrm{S}$ sector are much larger, which may be attributed to the dominance of southerly winds at station TAE (Fig. 2). Station TAE is located in complex orographic surroundings that the model resolution is too coarse to resolve, resulting in a lower wind direction quality in the $\mathrm{S}$ sector. Overall, the variability of the wind directions in the different sectors may arise from several possible reasons, amongst which are: the accuracy of the measurements at the different wind speed intensities, whether the model resolution is sufficiently high to resolve the complex coastal orography, and whether the model is able to represent the synoptic or weather patterns that stem the winds in the area.

Table 4 also shows that CCLM-ERAint and CCLM-JRA55 generally offer better reproductions of the wind direction in the N, NE, and NW sectors, which are characterized by relatively large percentages of high wind speeds compared with the other sectors, whereas CCLM-CFSR performs better in the E, SE, and S sectors, which have larger percentages of low wind speeds. This result again confirms that CCLM-ERAint and CCLM-JRA55 tend to offer a better performance for high winds than CCLMCFSR, not only in terms of wind speed, as shown in Table 3, but also in terms of wind direction.

Figure 5 shows the dependence of the wind direction residuals and error variability on the binned observed wind speeds at all available stations. This figure clearly shows that the variability of the wind direction residuals decreases with increasing wind speed. Furthermore, as shown in Fig. 5, the CCLMNCEP1 results tend to have a larger error variability than the results of the other three modeled results, and the direction residuals of this simulation (approxi- 


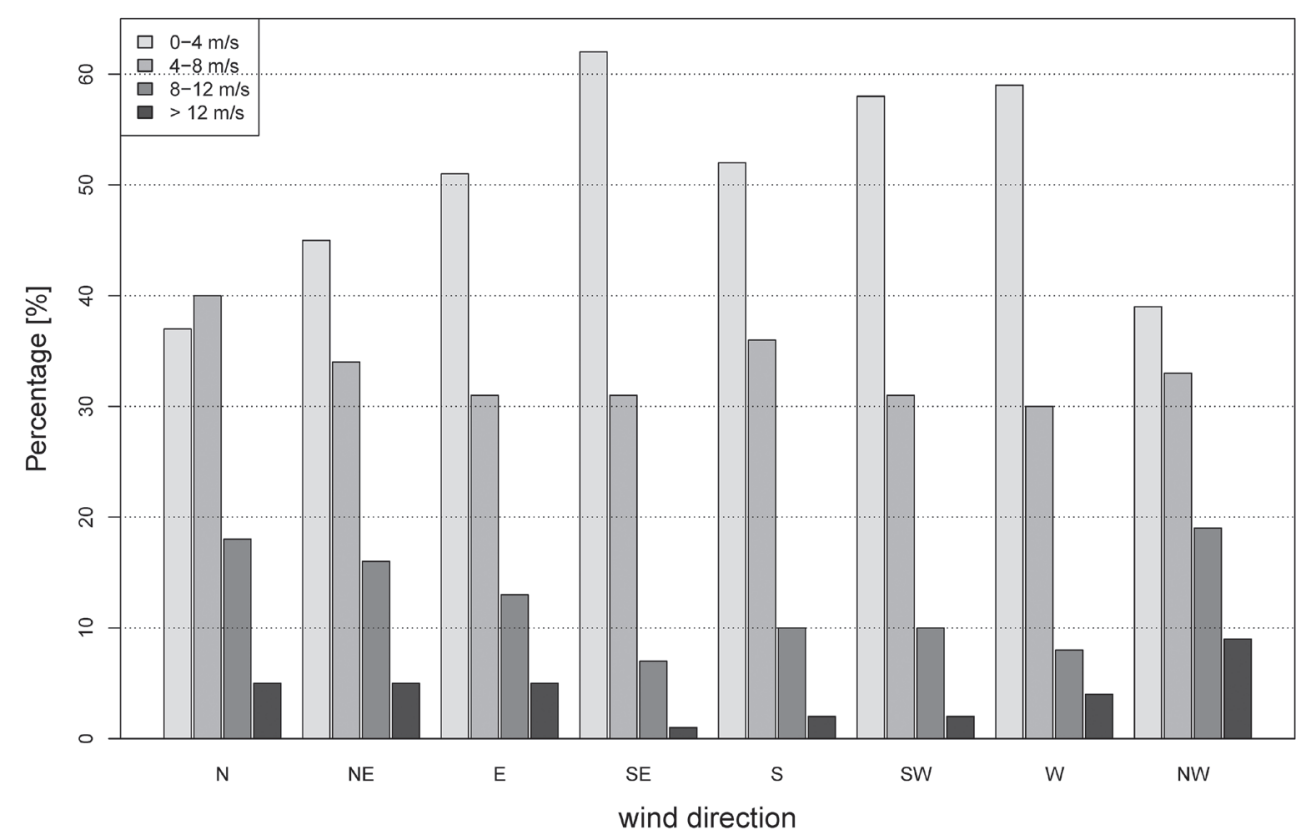

Fig. 4. Percentages of different wind intensities in the eight wind direction sectors based on six observation sites.

mately $10^{\circ}$ ) are also larger for wind speeds between 0 and $10 \mathrm{~m} \mathrm{~s}^{-1}$ than those of the other simulations; meanwhile, the direction residuals and error variability are quite similar among the results of CCLMCFSR, CCLM-ERAint, and CCLM-JRA55, with small positive residuals (approximately $3^{\circ}$ ) at wind speeds between 0 and $6 \mathrm{~m} \mathrm{~s}^{-1}$ and negative residuals (approximately $-5^{\circ}$ ) for wind speeds between 10 and $14 \mathrm{~m} \mathrm{~s}^{-1}$. Winds over $18 \mathrm{~m} \mathrm{~s}^{-1}$ are included only for reference, because the samples corresponding to such conditions are sparse and the measurements are less reliable because such weather conditions are poor for observations because of buoy oscillations owing to surface layer distortion (Large et al. 1995).

Figure 6 shows that the wind speed residuals are positive for all wind direction sectors and all simulations, of which the CCLM-NCEP1 results are characterized by the largest bias and variability. The residuals and variability are quite similar among the results of the other simulations, with the residuals being larger in the SE, S, SW, and W sectors than in the other sectors. The wind speed residuals of CCLM-CFSR in the N, NE, and NW sectors, which benefit from the superior performance of this model at low wind speeds, are smaller than those of CCLMERAint and CCLM-CFSR.

\subsection{Wind speed distributions}

The distributions of the modeled and observed wind speeds are displayed in Fig. 7 for all stations using box-and-whisker plots (Brase and Brase 2011). The length of the box between Q1 and Q3, which is the interquartile range, is a general measure of the data dispersion. Figure 7 shows that the observed and CCLM-NCEP1 wind speeds have similar box lengths, representing much larger wind speed dispersions than those of the other simulated winds. However, the values of Q1, Q2, Q3, and the 99th percentile for the CCLM-NCEP1 wind products at all stations are larger than those of the observations and other modeled winds. In terms of the CCLM-CFSR, CCLM-ERAint, and CCLM-JRA55 wind speeds, the Q1, Q2, Q3, and 99th-percentile values differ only slightly among the simulations, with the values of Q1, Q2, and Q3 being larger, and the 99th-percentile values being smaller than the observed results at most stations. The median values of CCLM-CFSR are slightly closer to the observed median values than are those of CCLMERAint, and CCLM-JRA55, whereas the extreme values of CCLM-ERAint and CCLM-JRA55 are slightly closer to the observed extreme values than are those of CCLM-CFSR. The performance of the modeled winds varies from station to station, and the largest differences from the observed data are 

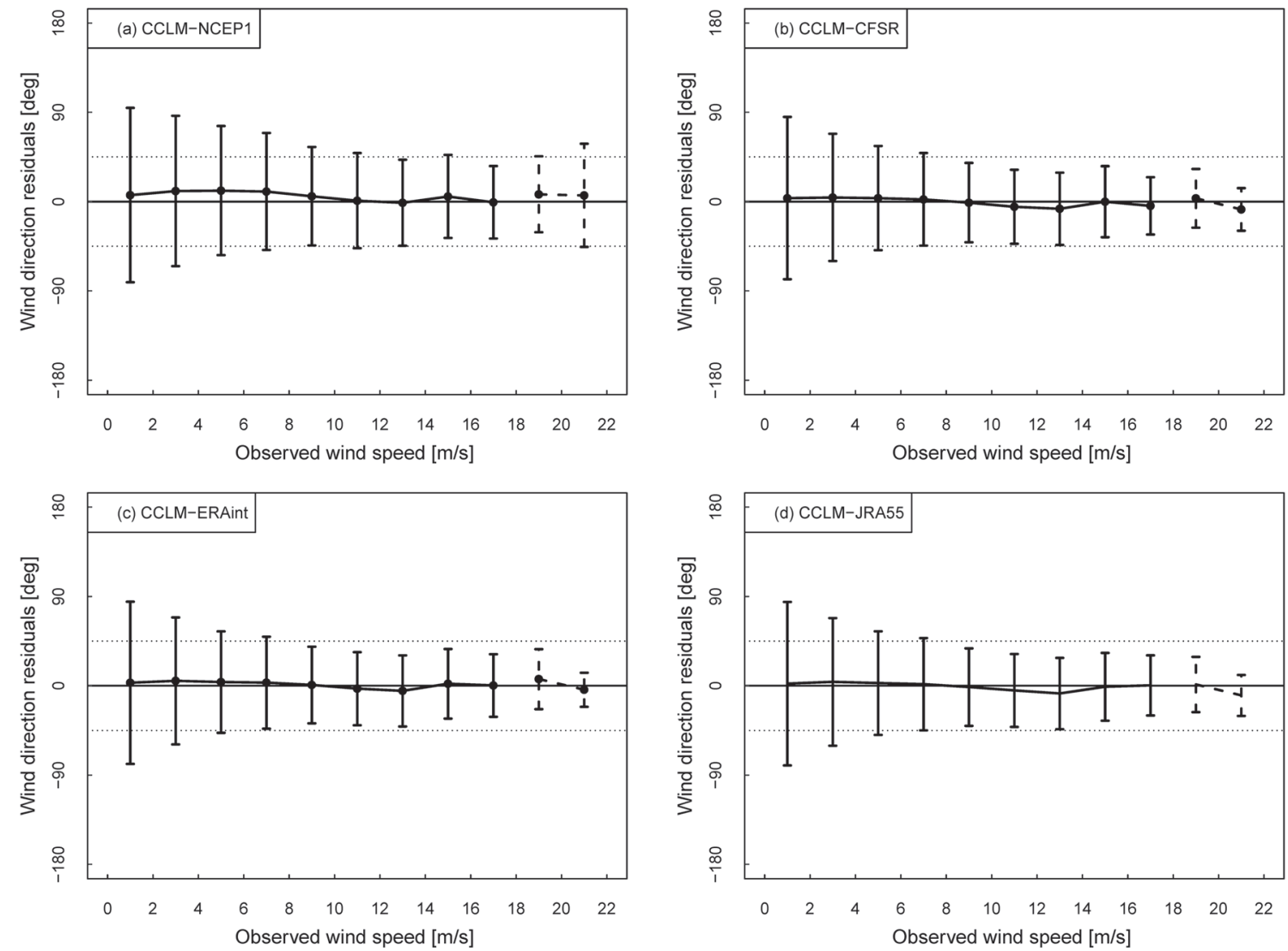

Fig. 5. Dependence of the wind direction residuals on the binned observed wind speeds at all available stations for the (a) CCLM-NCEP1 wind products, (b) CCLM-CFSR wind products, (c) CCLM-ERAint wind products and (d) CCLM-JRA55 wind products. The black points represent the average residuals based on 2-m s${ }^{-1}$ bins, and the bars represent the standard deviations.

found at station TAE, which is located in an area with complex coastal orography. Furthermore, the results indicate that the stations to the south (i.e., S02, S03, and IEO) should generally experience higher wind speeds than should the stations to the north (INC, S01, SEO, and TAE), which is consistent with the observed results presented in Section 3.1. The observed extreme winds (99th percentile) are strongest at station $\mathrm{S} 03\left(16.7 \mathrm{~m} \mathrm{~s}^{-1}\right)$, followed by stations IEO $\left(15.4 \mathrm{~m} \mathrm{~s}^{-1}\right)$ and $\mathrm{S} 02\left(15.4 \mathrm{~m} \mathrm{~s}^{-1}\right)$; these extremes are underestimated by CCLM-CFSR, CCLM-ERAint, and CCLM-CFSR, with underestimation ranging $0.8-2.5 \mathrm{~m} \mathrm{~s}^{-1}$, and overestimated by CCLM-NCEP1 with values $0.5-0.8 \mathrm{~m} \mathrm{~s}^{-1}$.

\section{Discussion}

\subsection{Influence of the temporal availability of measurements}

From Table 1, we see that the number of valid records at some stations is less than 7000 and as low as approximately 4500 for station IEO; the uncertainties introduced by the temporal availability of the measurements may have some influence on the conclusions made in Section 3. Therefore, the simulated data sets are used as references to investigate the influence of the temporal limitations of data sets on the statistics considered previously. Comparisons are performed between the temporal masked simulated data (MSD) and the complete simulated data (CMD) at all stations in the year 2006. A similar method has been used in a hindcast of the surface winds over the Iberian Peninsula by Lorente-Plazas et al. (2014). 

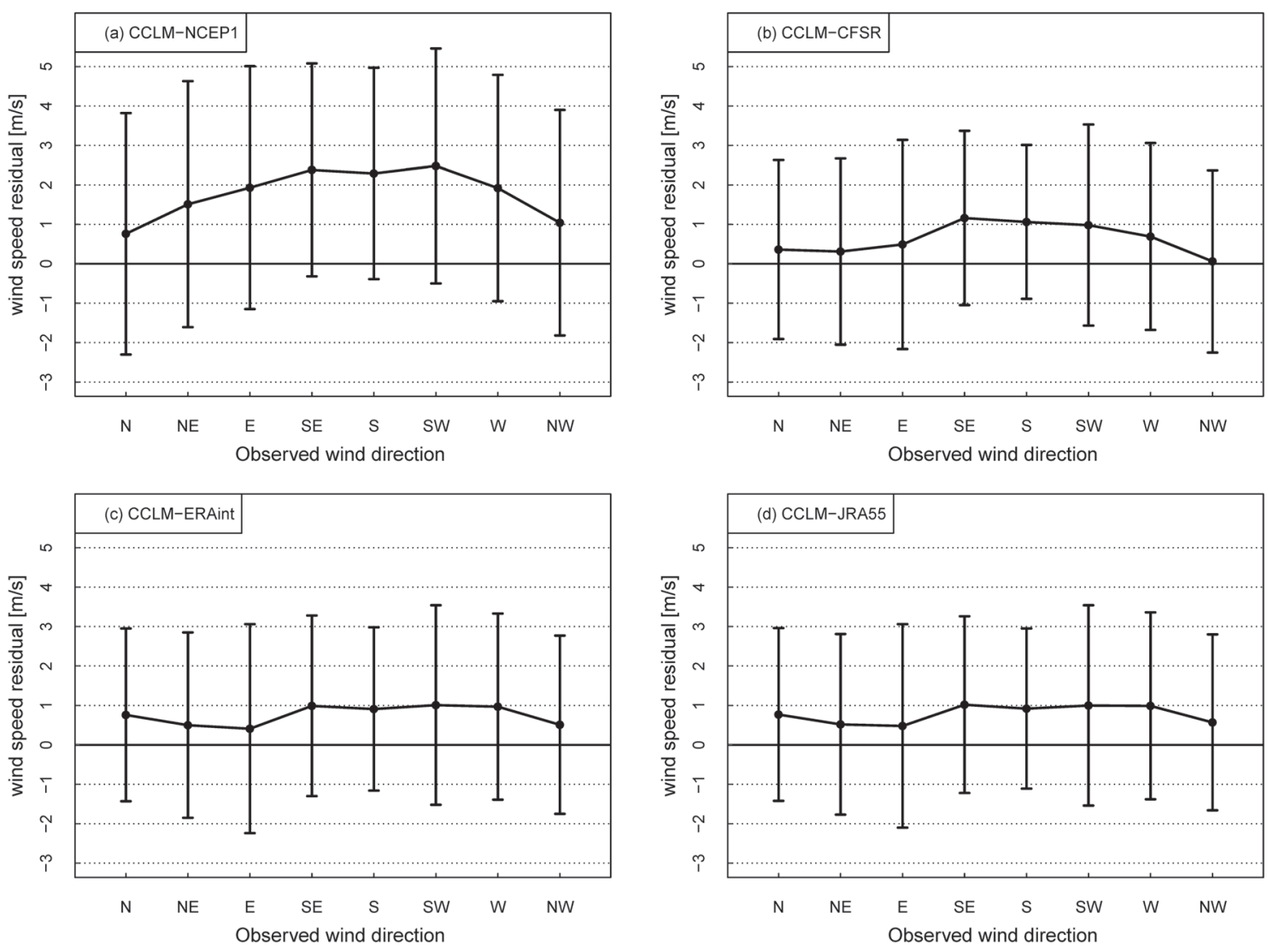

Fig. 6. Dependence of the wind speed residuals on the binned observed wind directions at all available stations for the (a) CCLM-NCEP1 wind products, (b) CCLM-CFSR wind products, (c) CCLM-ERAint wind products and (d) CCLM-JRA55 wind products. The black points represent the average residuals based on the eight direction sectors, and the bars represent the standard deviations.

The weight-averaged means and standard deviations for the MSD and CMD reveal minor differences between the MSD and CMD, with values less than $0.03 \mathrm{~m} \mathrm{~s}^{-1}$ (not shown here). Furthermore, the wind distributions and fitted Weibull distributions for the MSD and CSD at all stations are shown in Fig. 8 for each downscaled simulation. This figure shows that the minor differences between the MSD and the CSD for each simulation are negligible. With regard to the wind direction, the wind roses have been plotted for each station and those of CCLM-ERAint have been used to evaluate the differences between the MSD and the CSD. As revealed by the figures (not shown here), the general features of the wind roses are similar between the MSD and the CSD for each station. The greatest change is observed for station IEO, where the CSD contains higher percentages of northern and northeastern winds than the MSD, but the differences are less than $5 \%$. Overall, the missing measurements in the present study can be concluded to have only a minor effect on the wind speed and direction features reported in Section 3.

\subsection{Intercomparison of forcing data sets and poten- tial added value from the CCLM}

As illustrated by Wang et al. (2004), the skill of an RCM is highly dependent on the quality of the driving data, consistency in dynamics and physics between the regional model and the large-scale forcing data sets, physical parameterizations, and chaotic nature of climate systems. Furthermore, Meissner et al. (2009) have demonstrated that the lateral boundary conditions contribute more strongly than the other aspects of the setup such as the horizontal resolution, time integration scheme, and physical parameterizations.

In our study, the model setup was identical for 

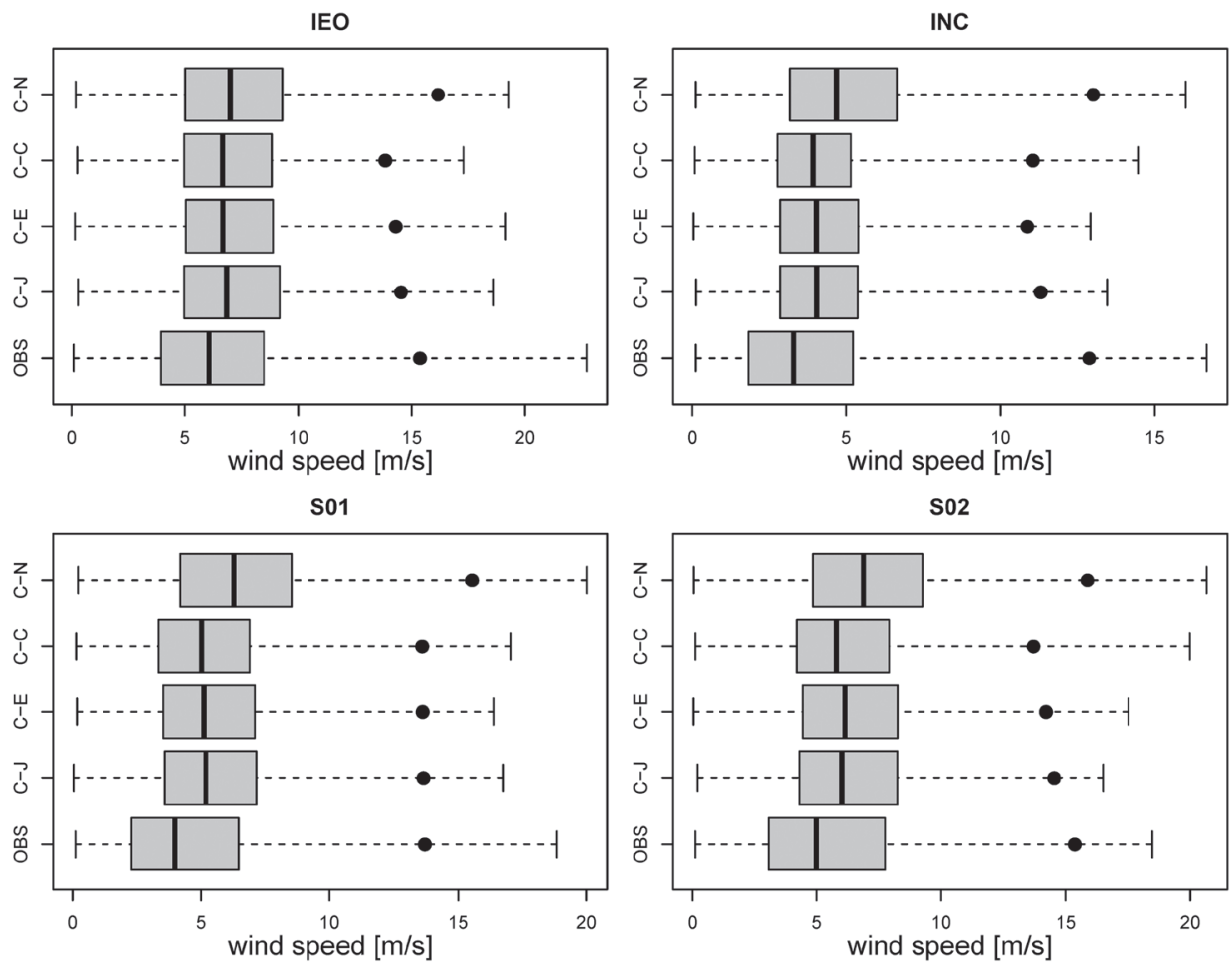

S03

SEO
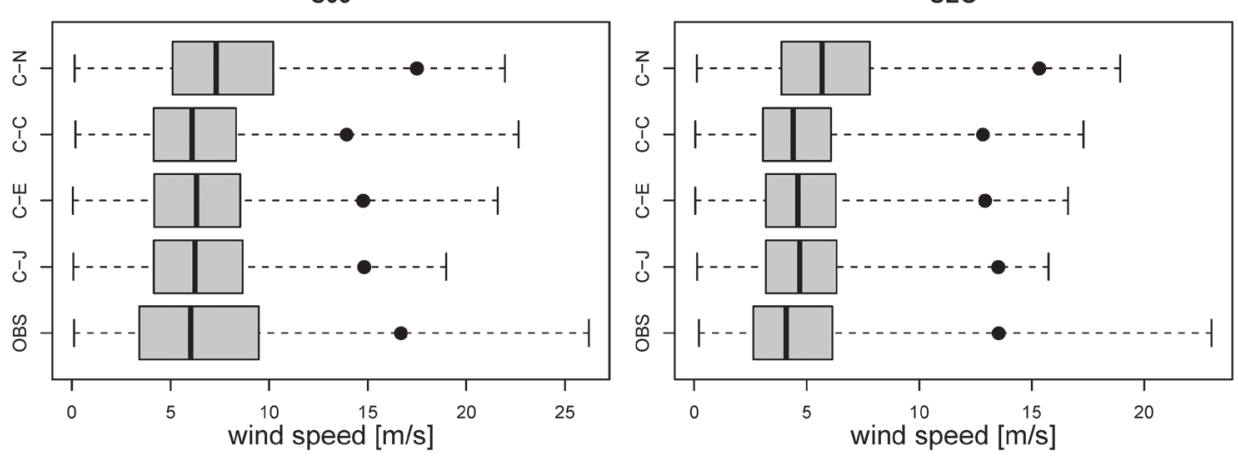

TAE
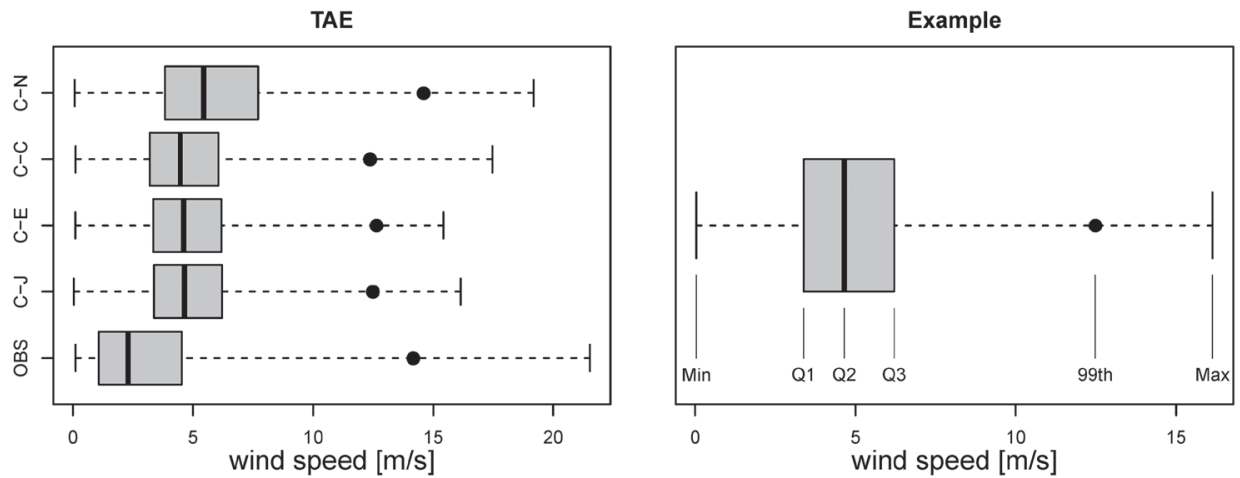

Fig. 7. Box and whisker plots showing the distributions of the modeled and observed wind speeds for all stations: Q1, Q2, and Q3 represent the 25th-, 50th-, and 75th-percentile wind speeds, respectively, whereas the black point represents the 99th-percentile wind speed. $\mathrm{C}-\mathrm{N}, \mathrm{C}-\mathrm{C}, \mathrm{C}-\mathrm{E}$ and $\mathrm{C}-\mathrm{J}$ are abbreviations for CCLM-NCEP1, CCLM-CFSR, CCLM-ERAint and CCLM-JRA55, respectively. 

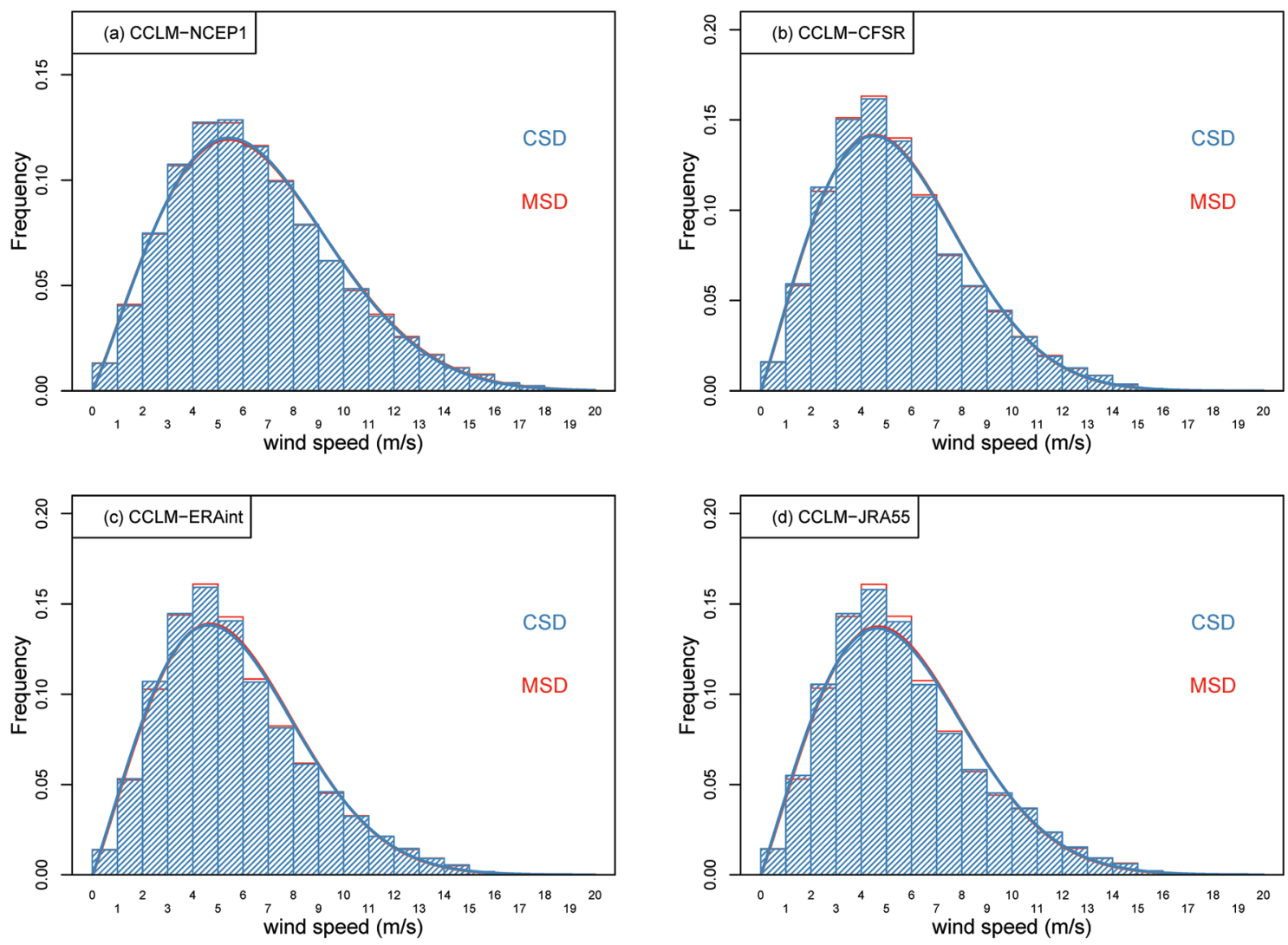

Fig. 8. The wind distributions and fitted Weibull distributions for the CSD (blue) and MSD (red) at all stations for each downscaled simulation: (a) CCLM-NCEP1, (b) CCLM-CFSR, (c) CCLM-ERAint, and (d) CCLM-JRA55.

each simulation except for the driving data set. Thus, the performance variations of the simulation results can be predominantly attributed to the quality of the forcing data sets. In Fig. 9, we show the differences in terms of a comparison between the forcing data sets and the observations for wind speed bins of $1 \mathrm{~m} \mathrm{~s}^{-1}$. All of the forcing data generally overestimate the wind speeds at values lower than approximately 6.5 $\mathrm{m} \mathrm{s}^{-1}$ and underestimate them at higher wind speeds of $6.5 \mathrm{~m} \mathrm{~s}^{-1}$ and above, leading to differences in the reproduction skills of the downscaled wind products at different wind intensities reported in Section 3.2. CCLM_55km is characterized by a systemic positive bias and a much larger error variance compared with CFSR, ERAint, and JRA55. However, compared with NCEP1, the wind bias of CCLM_55km is much lower for strong winds, whereas the error variance of the CCLM_55km data is still higher because of its high variability. CFSR, ERAint, and JRA55 exhibit quite consistent standard deviation errors, but their bias results show some differences, with ERAint being the worst in the case of strong winds and CFSR being the worst for light winds, reversed with respect to the results for the downscaled products. Thus, the qualities of the hindcasts are predominantly determined by the driving data sets; however, certain other factors are also of great importance such as the consistency between the hindcasts and the driving data sets.

One of the most intriguing issues related to RCMs is whether the added value can be generated through dynamical downscaling. To investigate this issue, the statistical measures and distribution features of the wind speeds at each station for the forcing and downscaled data sets are considered for comparison with the observations. As examples, two of the stations (SEO and IEO) are represented in Fig. 10 and Fig. 11. We can clearly observe the presence of added value in the wind distribution and bias reduction at station SEO for CCLM-CFSR (Fig. 10b) and CCLMERAint (Fig. 10c), but this is not the case at station IEO (Fig. 11). Considering the statistical measures (bias, correlation coefficient, and RMSE) for each 


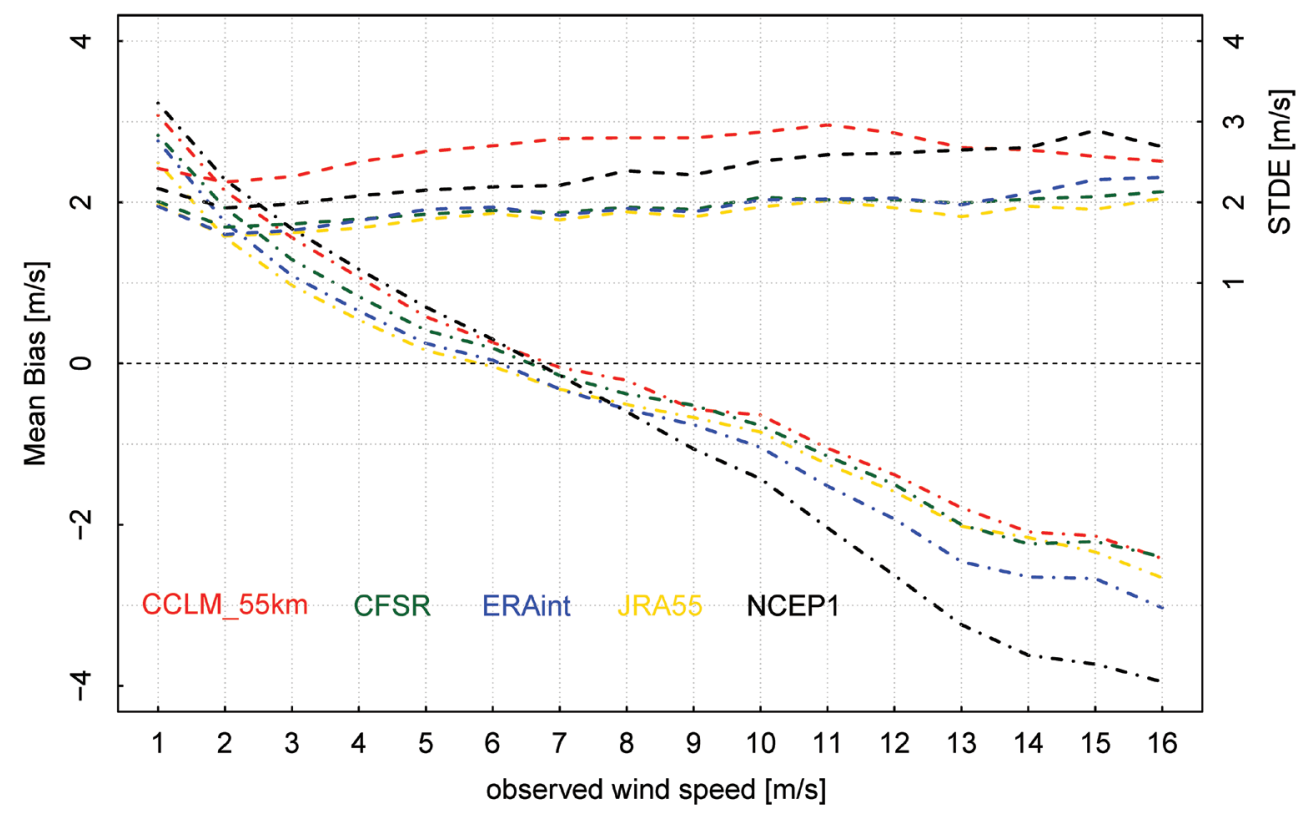

Fig. 9. Comparisons of conditional bias (dash-dotted lines) in wind speed and standard deviation error (dashed lines) between the forcing data sets and the observations at the seven stations; the conditioning is performed on the strength of the observed wind, in bins of $1 \mathrm{~m} \mathrm{~s}^{-1}$.

station (not shown here), we find more cases of which these measures degrade with the downscaling for JRA55 and CCLM 55km than cases of which they improve. The cases are general equally distributed for the downscaling of ERAint and CFSR and the first downscaling of NCEP1; in terms of wind distribution, there are more cases that exhibit improvement than the deterioration for the downscaling of ERAint and JRA55 and the first downscaling of NCEP1.

Furthermore, we investigate whether the value added to the statistical measures by the CCLM is related to the wind intensity. As shown in Fig. 12, there is no bias reduction for any downscaled simulation relative to its driving data set at low wind speeds, whereas at high wind speeds, a large bias reduction is achieved for the NCEP1 downscaled simulations CCLM_55km and CCLM-NCEP1 (Fig. 12a) and the bias is reduced slightly by downscaling ERAint and JRA55 (Figs. 12c, d), while CCLM-CFSR has a larger bias than does CFSR (Fig. 12b). In terms of the standard deviation error, the forcing and downscaled data sets show similar results (with the exception of the NCEP1 downscaling simulations, where a greater standard deviation error is induced by CCLM_55km).

Overall, the performances of the hindcast simulations are generally consistent with the reproduction capability of their driving data sets, thereby demon- strating the importance of the forcing data. Nevertheless, some system error can be induced by the RCM itself, including the error because of the spatial and temporal interpolation of the forcing data or issues related to the consistency of dynamics and physics between the regional model and the large scale forcing data set. For our research domain, NCEP1 would be the least desirable choice because its statistical measures are the worst among all of the reanalyses; CCLM_55km offers some improvement in several cases relative to NCEP1, but it is still worse than the other three reanalyses. For CFSR, ERAint, and JRA55, their statistical measures and wind distributions are similar. In terms of added value, we conclude that CCLM-ERAint and CCLM-JRA55 may possibly outperform CCLM-CFSR and CCLMNCEP1, especially at high wind speeds; however, we cannot obtain a robust conclusion regarding the added value from the downscaling and its dependence on the driving data sets because the available observation sites are limited and the spatial distributions of the potential added value vary considerably. Further study is needed regarding the added value.

\section{Conclusion}

In this study, we compared the relative performance of downscaling strategies using different reanalyses 

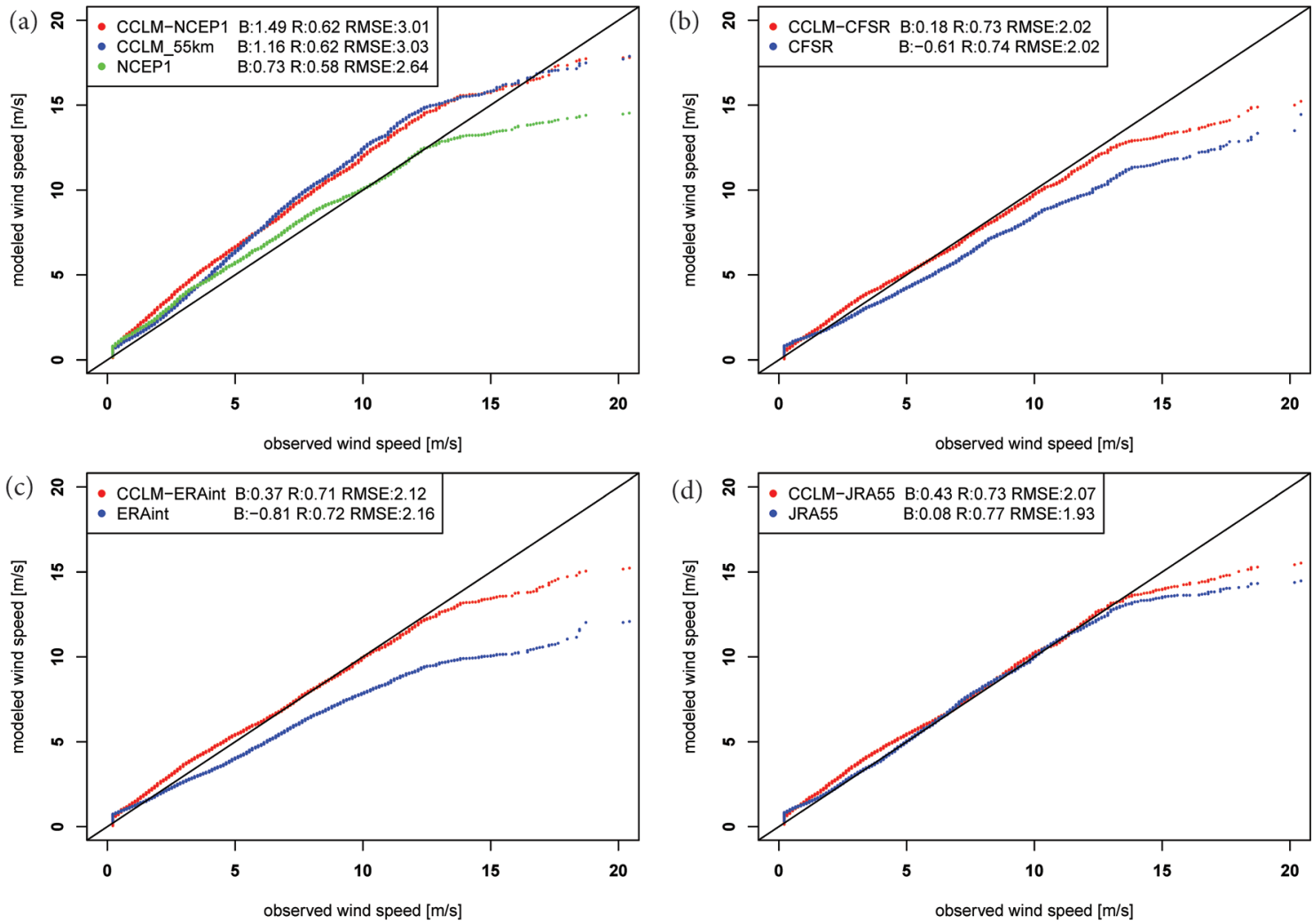

Fig. 10. The qq-plots and statistical measures (B: bias, R: correlation coefficient) for the forcing and downscaled data sets at station SEO: (a) CCLM-NCEP1, CCLM_55km and NCEP1, (b) CCLM-CFSR and CFSR, (c) CCLM-ERAint and ERAint, and (d) CCLM-JRA55 and JRA55.

to constrain a regional climate model. Not surprisingly, the driving reanalyses that offer higher spatial resolution and better data coverage fare better than, particularly the NCEP1 data set. The latter describes the synoptic state on a considerably coarser grid; the higher resolution required for the forcing of the $7-\mathrm{km}$ simulation is achieved via an initial downscaling step. The fact that this description is inferior to that of, for instance, ERAint is to be expected, and our analysis confirms this expectation.

Therefore, the NCEP1-driven analysis is less accurate than, for instance, ERAint when both are available. However, this result does not imply that a simulation using NCEP1, particularly when performed without the intermediate CCLM "interpolation," does not provide a useful analysis of past weather. The primary advantage of such an NCEP1-constrained simulation is the much longer term availability of NCEP1, namely, from at least 1958, if not 1948. For most of the Northern Hemisphere, the processes constrained by the large scale portion of NCEP1 are considered to be mostly homogeneous, although there may be some exceptions, for instance, in central Asia (Klehmet 2014). Various studies have demonstrated the added value and utility of such a simulation on a 50-km grid (Weisse et al. 2009; Feser et al. 2011), which can provide a mostly homogeneous description for 60 or more years. For shorter time scales, a more accurate analysis may be derived from more accurate drivers, as demonstrated in the present study.

In the preceding sections, we investigated the observed wind characteristics as well as the suitability of dynamical downscaling for describing the local wind conditions at a number of stations along the coast of the Yellow Sea. Four global reanalyses, i.e., NCEP1, CFSR, ERAint and JRA55, were fed into the 7-km-grid regional atmospheric model CCLM using spectral nudging. The comparison was performed for the year 2006, where good observational data were available. A comprehensive statistical analysis was conducted, focusing on the intercomparison of wind data downscaled from different forcing data sets. 

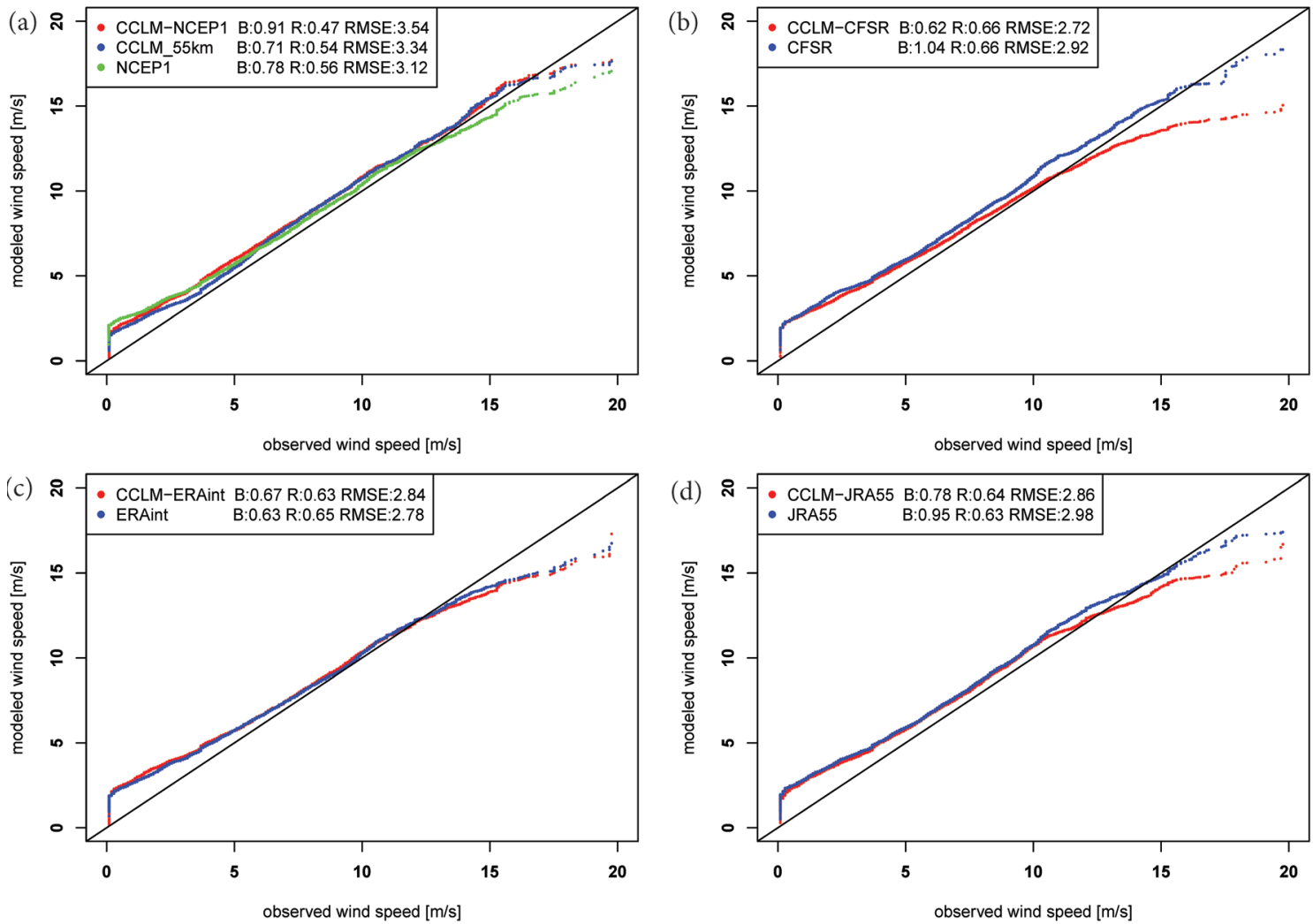

Fig. 11. The same as Fig. 10 but for station IEO.

The main conclusions drawn from this study can be summarized as follows:

- The wind speed along the western coast of the Korean Peninsula generally increases from north to south, with light winds being dominant and prevailing in the northerly and northwesterly directions at the northern stations, whereas the southern coast of the Peninsula is characterized by the highest annual mean wind speed and the highest percentage of strong winds, primarily because of the intensification because of the topography of the Korean Peninsula and the Island of Jeju, or Tsushima.

- The downscaled simulations yield good quality wind speed products. However, they all tend to overestimate observed low wind speeds and underestimate observed high wind speeds; they are better at reproducing intermediate winds (4-12 $\mathrm{m} \mathrm{s}^{-1}$ ). CCLM-CFSR, CCLM-ERAint, and CCLM-JRA55 are consistent in their reproduction of wind speeds and directions, with CCLMERAint and CCLM-JRA55 being slightly better than CCLM-CFSR for strong winds and vice versa for light winds. All three offers better performance than does CCLM-NCEP1 in reproducing local winds.

- The accuracy of the modeled wind direction is strongly associated with the wind speed intensity; all simulations tend to produce better results for wind directions associated with strong winds.

With their higher spatial resolution and more advanced assimilation and correction techniques, the CFSR, ERAint, and JRA55 data sets exhibit much better capabilities of reproducing local wind speeds than does NCEP1 in the area under study. In addition, some integration errors may accumulate during the downscaling from NCEP1 to first CCLM_55km and then CCLM-NCEP1, which leads to poorer quality of the modeled wind speeds upon downscaling from NCEP1 compared with that achieved by directly downscaling from CFSR, ERAint, and JRA55. Based on the results presented in this work, JRA55, ERAint, and CFSR can provide reliable initial and boundary conditions for RCMs in our research domain. For 

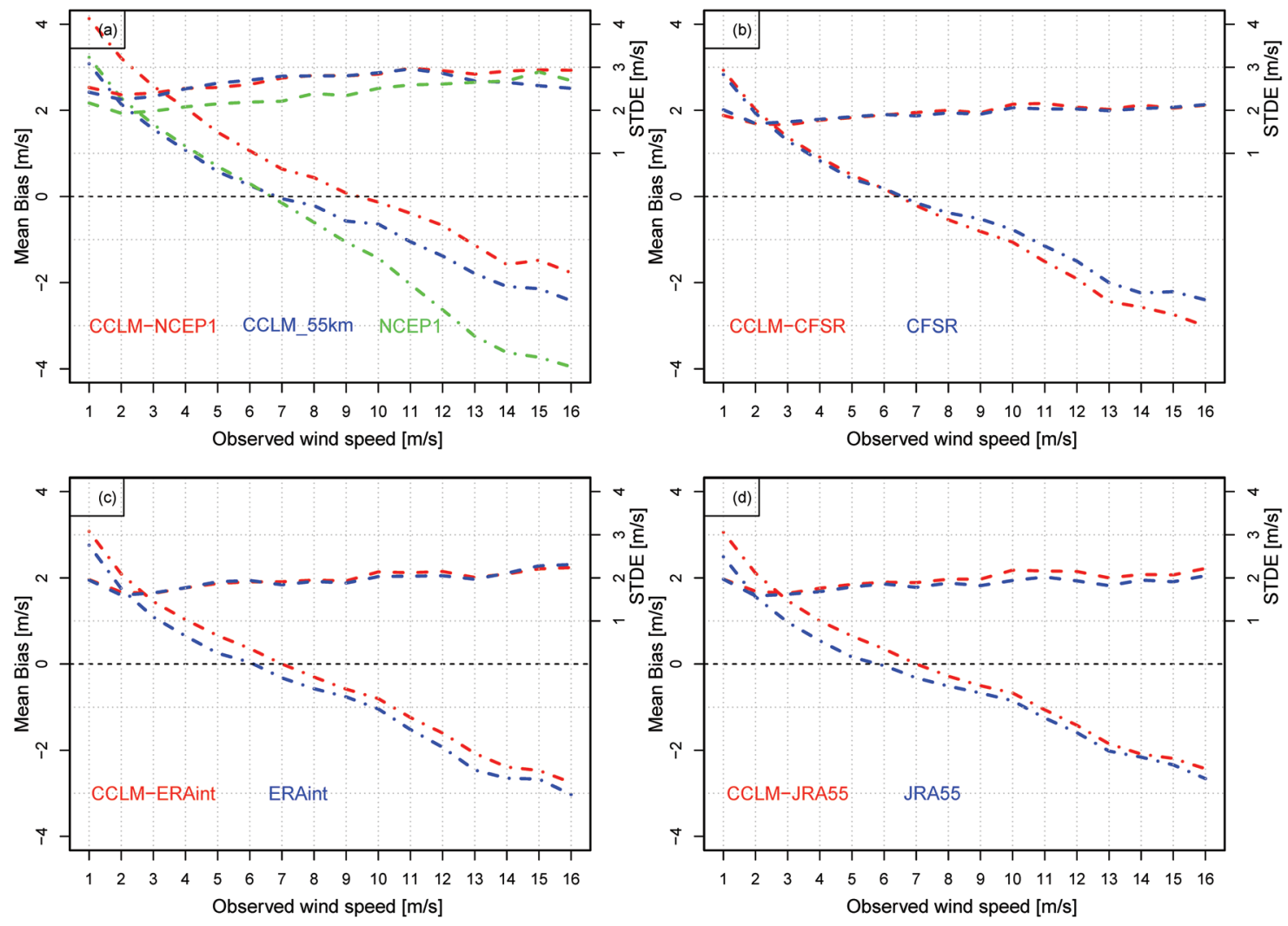

Fig. 12. The same as Fig. 9 but for (a) CCLM-NCEP1, CCLM_55km and NCEP1; (b) CCLM-CFSR and CFSR; (c) CCLM-ERAint and ERAint; and (d) CCLM-JRA55 and JRA55.

longer time scales, JRA55 is preferred for long-term climate studies and certain other potential applications in climate simulations.

High-resolution $(7 \mathrm{~km})$ simulations enable more realistic physiographic forcing features such as complex orography, and coastlines. It is expected that there may be some potential added value arising from dynamical downscaling because meso-scale phenomena, such as meso-cyclones and orographically induced wind flows and fronts, can be resolved by means of downscaling simulations instead of using coarse resolution reanalysis data sets. However, no robust proof of such an added value has been obtained in the present study, possibly as a result of temporal or spatial limitations of the observations in the research domain. Further investigations of the potential for added value will be performed in the future based on the available QuikSCAT field observations and longterm simulation data, similar to the work conducted by Winterfeldt et al. (2011) in northern Europe.

\section{Acknowledgments}

We are grateful to the China Scholarship Council (CSC201206330070) for awarding the first author with funding for four years of study abroad at the Helmholtz-Zentrum Geesthacht (HZG) and to the REKLIM project for financial support for this research. The authors thank B. Rockel and F. Feser for valuable discussions. We appreciate the contributions of the following people and institutions who provided and assisted with the data: CCLM_55km data were supplied by F. Feser (HZG), observation data were provided by the National Marine Data and Information Service of China (NMDIS) and by Y. K. Seo (Korean Meteorological Administration) and K. J. Ha (Pusan National University), and the reanalysis data sets were obtained as follows: NCEP1 and CFSR from NCEP/NCAR, ERAint from ECMWF, and JRA55 from JMA. We also acknowledge the German Climate Computing Center (DKRZ) for providing the computer hardware used for the simulations. 


\section{References}

Accadia, C., S. Zecchetto, A. Lavagnini, and A. Speranza, 2007: Comparison of $10-\mathrm{m}$ wind forecasts from a regional area model and QuikSCAT Scatterometer wind observations over the Mediterranean Sea. Mon. Wea. Rev., 135, 1945-1960.

Alvarez, I., M. Gomez-Gesteira, M. deCastro, and D. Carvalho, 2013: Comparison of different wind products and buoy wind data with seasonality and interannual climate variability in the southern Bay of Biscay (2000-2009). Deep Sea Res. Part 2: Top. Stud. Oceanogr., 106, 38-48.

Artioli, Y., G. Bendoricchio, and L. Palmeri, 2005: Defining and modelling the coastal zone affected by the Po River (Italy). Ecol. Model., 184, 55-68.

Atlas, R., R. N. Hoffman, J. Ardizzone, S. M. Leidner, J. C. Jusem, D. K. Smith, and D. Gombos, 2011: A cross-calibrated, multiplatform ocean surface wind velocity product for meteorological and oceanographic applications. Bull. Amer. Meteor. Soc., 92, 157-174.

Baldauf, M., A. Seifert, J. Förstner, D. Majewski, M. Raschendorfer, and T. Reinhardt, 2011: Operational convective-scale numerical weather prediction with the COSMO model: Description and sensitivities. Mon. Wea. Rev., 139, 3887-3905.

Barcikowska, M., 2012: Variability and trends of tropical cyclones over the western North Pacific for the last decades. Ph.D. thesis, University of Hamburg.

Berge, E., Ø. Byrkjedal, Y. Ydersbond, D. Kindler, and A. Kjeller Vindteknikk, 2009: Modelling of offshore wind resources. Comparison of a meso-scale model and measurements from FINO 1 and North Sea oil rigs. Proceedings of European Wind Energy Conference 2009, Marseille, France.

Böhm, U., M. Kücken, W. Ahrens, A. Block, D. Hauffe, K. Keuler, B. Rockel, and A. Will, 2006: CLM-the climate version of LM: Brief description and longterm applications. COSMO Newsletter, 6, 225-235.

Brase, C. H., and C. P. Brase, 2011: Understandable Statistics: Concepts and Methods, 10th edition. Cengage Learning, $822 \mathrm{pp}$.

Carvalho, D., A. Rocha, and M. Gómez-Gesteira, 2012: Ocean surface wind simulation forced by different reanalyses: Comparison with observed data along the Iberian Peninsula coast. Ocean Modelling, 56, 31-42.

Carvalho, D., A. Rocha, M. Gómez-Gesteira, and C. S. Santos, 2014a: Comparison of reanalyzed, analyzed, satellite-retrieved and NWP modelled winds with buoy data along the Iberian Peninsula coast. Remote Sens. Environ., 152, 480-492.

Carvalho, D., A. Rocha, M. Gómez-Gesteira, and C. Silva Santos, 2014b: Offshore wind energy resource simulation forced by different reanalyses: Comparison with observed data in the Iberian Peninsula. Appl.
Energ., 134, 57-64.

Chawla, A., D. M. Spindler, and H. L. Tolman, 2013: Validation of a thirty year wave hindcast using the climate forecast system reanalysis winds. Ocean Modelling, 70, 189-206.

Chelliah, M., W. Ebisuzaki, S. Weaver, and A. Kumar, 2011: Evaluating the tropospheric variability in National Centers for Environmental Prediction's climate forecast system reanalysis. J. Geophys. Res., 116, D17107, doi:10.1029/2011JD015707.

Dee, D. P., S. M. Uppala, A. J. Simmons, P. Berrisford, P. Poli, S. Kobayashi, U. Andrae, M. A. Balmaseda, G. Balsamo, P. Bauer, P. Bechtold, A. C. M. Beljaars, L. van de Berg, J. Bidlot, N. Bormann, C. Delsol, R. Dragani, M. Fuentes, A. J. Geer, L. Haimberger, S. B. Healy, H. Hersbach, E. V. Hólm, L. Isaksen, P. Kållberg, M. Köhler, M. Matricardi, A. P. McNally, B. M. Monge-Sanz, J.-J. Morcrette, B.-K. Park, C. Peubey, P. de Rosnay, C. Tavolato, J.-N. Thépaut, and F. Vitart., 2011: The ERA-Interim reanalysis: Configuration and performance of the data assimilation system. Quart. J. Roy. Meteor. Soc., 137, 553-597.

Dee, D., and National Center for Atmospheric Research Staff, 2013: The climate data guide: ERA-interim. [Available at https://climatedataguide.ucar.edu/ climate-data/era-interim.]

Denis, B., R. Laprise, D. Caya, and J. Côté, 2002: Downscaling ability of one-way nested regional climate models: The big-brother experiment. Climate Dyn., 18, 627-646.

Doms, G., and U. Schättler, 2002: A description of the nonhydrostatic regional model LM. Part I: Dynamics and numerics. Deutscher Wetterdienst Tech. Report, $140 \mathrm{pp}$.

Ebita, A., S. Kobayashi, Y. Ota, M. Moriya, R. Kumabe, K. Onogi, Y. Harada, S. Yasui, K. Miyaoka, K. Takahashi, H. Kamahori, C. Kobayashi, H. Endo, M. Soma, Y. Oikawa, and T. Ishimizu, 2011: The Japanese 55-year Reanalysis "JRA-55": An interim report. SOLA, 7, 149-152.

Enriquez, A. G., and C. A. Friehe, 1995: Effects of wind stress and wind stress curl variability on coastal upwelling. J. Phys. Oceanogr., 25, 1651-1671.

Feser, F., B. Rockel, H. von Storch, J. Winterfeldt, and M. Zahn, 2011: Regional climate models add value to global model data: A review and selected examples. Bull. Amer. Meteor. Soc., 92, 1181-1192.

Jimenez, B., F. Durante, B. Lange, T. Kreutzer, and J. Tambke, 2007: Offshore wind resource assessment with WAsP and MM5: Comparative study for the German Bight. Wind Energ., 10, 121-134.

Kalnay, E., M. Kanamitsu, R. Kistler, W. Collins, D. Deaven, L. Gandin, M. Iredell, S. Saha, G. White, J. Woollen, Y. Zhu, M. Chelliah, W. Ebisuzaki, W. Higgins, J. Janowiak, K. C. Mo, C. Ropelewski, J. Wang, A. Leetmaa, R. Reynolds, R. Jenne, and D. 
Joseph, 1996: The NCEP/NCAR 40-year reanalysis project. Bull. Amer. Meteor. Soc., 77, 437-471.

Kanamaru, H., and M. Kanamitsu, 2007: Scale-selective bias correction in a downscaling of global analysis using a regional model. Mon. Wea. Rev., 135, 334-350.

Kessler, E., 1969: On the distribution and continuity of water substance in atmosferic circulations. Meteor. Monogr., 10, 1-84.

Kistler, R., E. Kalnay, W. Collins, S. Saha, G. White, J. Woollen, M. Chelliah, W. Ebisuzaki, M. Kanamitsu, V. Kousky, H. van den Dool, R. Jenne, and M. Fiorino, 2001: The NCEP-NCAR 50-year reanalysis: Monthly means CD-ROM and documentation. Bull. Amer. Meteor. Soc., 82, 247-267.

Klehmet, K., 2014: A model-based reconstruction of recent Siberian climate-focusing on snow cover. Ph.D. thesis, University of Hamburg.

Large, W. G., J. Morzel, and G. B. Crawford, 1995: Accounting for surface wave distortion of the marine wind profile in low-level ocean storms wind measurements. J. Phys. Oceanogr., 25, 2959-2971.

Liu, F., J. Su, A. Moll, H. Krasemann, X. Chen, T. Pohlmann, and K. Wirtz, 2014: Assessment of the summer-autumn bloom in the Bohai Sea using satellite images to identify the roles of wind mixing and light conditions. J. Mar. Syst., 129, 303-317.

Liu, P., A. P. Tsimpidi, Y. Hu, B. Stone, A. G. Russell, and A. Nenes, 2012: Differences between downscaling with spectral and grid nudging using WRF. Atmos. Chem. Phys., 12, 3601-3610.

Lorente-Plazas, R., J. P. Montávez, S. Jerez, J. J. Gómez-Navarro, P. Jiménez-Guerrero, and P. A. Jiménez, 2014: A 49 year hindcast of surface winds over the Iberian Peninsula. Int. J. Climatol., 35, 3007-3023.

Meissner, C., G. Schädler, H.-J. Panitz, H. Feldmann, and C. Kottmeier, 2009: High-resolution sensitivity studies with the regional climate model COSMO-CLM. Meteor. Z., 18, 543-557.

Ohsawa, T., N. Tubouchi, R. Niwa, J. Tanemoto, S. Shimada, and Y. Takeyama, 2011: Characteristics of offshore wind speed simulated with WRF in the seas around Japan. Proceedings of European Wind Energy Association Offsore 2011. Amsterdam, Netherlands, $1-9$.

Ohsawa, T., S. Shimada, D. Heinemann, G. Steinfeld, M. Schmidt, L. von Bremen, and J. Tambke, 2013: Offshore wind resource maps in German coastal waters based on WRF simulation. Proceedings of European Wind Energy Association Offshore 2013. Frankfurt, Germany, 1-8.

Onogi, K., J. Tsutsui, H. Koide, M. Sakamoto, S. Kobayashi, H. Hatsushika, T. Matsumoto, N. Yamazaki, H. Kamahori, K. Takahashi, S. Kadokura, K. Wada, K. Kato, R. Oyama, T. Ose, N. Mannoji, and R. Taira., 2007: The JRA-25 Reanalysis. J. Meteor. Soc. Japan, 85, 369-432.

Penabad, E., I. Alvarez, C. Balseiro, M. DeCastro, B. Gómez, V. Pérez-Muñuzuri, and M. Gómez-Gesteira, 2008: Comparative analysis between operational weather prediction models and QuikSCAT wind data near the Galician coast. J. Mar. Syst., 72, 256-270.

Pielke, R. A., 1991: A recommended specific definition of 'resolution'. Bull. Amer. Meteor. Soc., 72, 1914-1914.

Ritter, B., and J.-F. Geleyn, 1992: A comprehensive radiation scheme for numerical weather prediction models with potential applications in climate simulations. Mon. Wea. Rev., 120, 303-325.

Saha, S., S. Moorthi, H.-L., Pan, X. Wu, J. Wang, S. Nadiga, P. Tripp, R. Kistler, J. Woollen, D. Behringer, H. Liu, D. Stokes, R. Grumbine, G. Gayno, J. Wang, Y.-T. Hou, H.-Y. Chuang, H.-M. H. Juang, J. Sela, M. Iredell, R. Treadon, D. Kleist, P. van Delst, D. Keyser, J. Derber, M. Ek, J. Meng, H. Wei, R. Yang, S. Lord, H. van den Dool, A. Kumar, W. Wang, C. Long, M. Chelliah, Y. Xue, B. Huang, J.-K. Schemm, W. Ebisuzaki, R. Lin, P. Xie, M. Chen, S. Zhou, W. Higgins, C.-Z. Zou, Q. Liu, Y. Chen, Y. Han, L. Cucurull, R. W. Reynolds, G. Rutledge, and M. Goldberg, 2010: The NCEP Climate Forecast System Reanalysis. Bull. Amer. Meteor. Soc., 91, 1015-1057.

Schrodin, R., and E. Heise, 2002: A new multi-layer soil model. COSMO Newsletter, 2, 149-151.

Shimada, S., T. Ohsawa, S. Chikaoka, and K. Kozai, 2011: Accuracy of the wind speed profile in the lower PBL as simulated by the WRF model. SOLA, 7, 109-112.

Sousa, M., I. Alvarez, N. Vaz, M. Gomez-Gesteira, and J. Dias, 2013: Assessment of wind pattern accuracy from the QuikSCAT satellite and the WRF model along the Galician coast (Northwest Iberian Peninsula). Mon. Wea. Rev., 141, 742-753.

Stull, R. B., 1988: An Introduction to Boundary Layer Meteorology. Kluwer Academic Publishers, 666 pp.

Su, J., and Y. Yuan, 2005: Hydrology in China Coastal Sea. Ocean Press, 367 pp (in Chinese).

Taylor, K. E., 2001: Summarizing multiple aspects of model performance in a single diagram. J. Geophys. Res., 106, 7183-7192.

Tiedtke, M., 1989: A comprehensive mass flux scheme for cumulus parameterization in large-scale models. Mon. Wea. Rev., 117, 1779-1800.

Toba, Y., N. Iida, H. Kawamura, N. Ebuchi, and I. S. Jones, 1990: Wave dependence of sea-surface wind stress. $J$. Phys. Oceanogr., 20, 705-721.

Uppala, S. M., P. W. Kållberg, A. J. Simmons, U. Andrae, V. Da Costa Bechtold, M. Fiorino, J. K. Gibson, J. Haseler, A. Hernandez, G. A. Kelly, X. Li, K. Onogi, S. Saarinen, N. Sokka, R. P. Allan, E. Andersson, K. Arpe, M. A. Balmaseda, A. C. M. Beljaars, L. Van De Berg, J. Bidlot, N. Bormann, S. Caires, F. Chevallier, A. Dethof, M. Dragosavac, M. Fisher, M. Fuentes, 
S. Hagemann, E. Hólm, B. J. Hoskins, L. Isaksen, P. A. E. M. Janssen, R. Jenne, A. P. McNally, J.-F. Mahfouf, J.-J. Morcrette, N. A. Rayner, R. W. Saunders, P. Simon, A. Sterl, K. E. Trenberth, A. Untch, D. Vasiljevic, P. Viterbo, and J. Woollen, 2005: The ERA-40 re-analysis. Quart. J. Roy. Meteor. Soc., 131, 2961-3012.

Vecchi, G. A., S. Fueglistaler, I. M. Held, T. R. Knutson, and M. Zhao, 2013: Impacts of atmospheric temperature trends on tropical cyclone activity. J. Climate, 26, 3877-3891.

von Storch, H., H. Langenberg, and F. Feser, 2000: A spectral nudging technique for dynamical downscaling purposes. Mon. Wea. Rev., 128, 3664-3673.

Wang, W., P. Xie, S.-H. Yoo, Y. Xue, A. Kumar, and X. Wu, 2011: An assessment of the surface climate in the NCEP climate forecast system reanalysis. Climate Dyn., 37, 1601-1620.

Wang, Y., L. R. Leung, J. L. McGREGOR, D.-K. Lee, W.-C. Wang, Y. Ding, and F. Kimura, 2004: Regional climate modeling: progress, challenges, and prospects. J. Meteor. Soc. Japan, 82, 1599-1628.

Weisse, R., and H. von Storch, 2010: Marine Climate and
Climate Change: Storms, Wind Waves and Storm Surges. Springer, 219 pp.

Weisse, R., H. von Storch, U. Callies, A. Chrastansky, F. Feser, I. Grabemann, H. Günther, A. Plüss, T. Stoye, J. Tellkamp, J. Winterfeldt, and K. Woth, 2009: Regional meteo-marine reanalyses and climate change projections: Results for Northern Europe and potentials for coastal and offshore applications. Bull. Amer. Meteor. Soc., 90, 849-860.

Winterfeldt, J., and R. Weisse, 2009: Assessment of value added for surface marine wind speed obtained from two regional climate models. Mon. Wea. Rev., 137, 2955-2965.

Winterfeldt, J., B. Geyer, and R. Weisse, 2011: Using QuikSCAT in the added value assessment of dynamically downscaled wind speed. Int. J. Climatol., 31, 10281039.

Wunsch, C., 1998: The work done by the wind on the oceanic general circulation. J. Phys. Oceanogr., 28, 2332-2340.

Young, I., S. Zieger, and A. Babanin, 2011: Global trends in wind speed and wave height. Science, 332, 451-455. 